\title{
Urban Turbulence Velocity Spectra From JU2003 Observation
}

\author{
by Sam Chang, Ananth Sridhar, Cheryl Klipp, and Giap Huynh
}




\section{NOTICES}

\section{Disclaimers}

The findings in this report are not to be construed as an official Department of the Army position unless so designated by other authorized documents.

Citation of manufacturer's or trade names does not constitute an official endorsement or approval of the use thereof.

Destroy this report when it is no longer needed. Do not return it to the originator. 


\section{Army Research Laboratory}

Adelphi, MD 20783-1138

ARL-TR-7157

December 2014

\section{Urban Turbulence Velocity Spectra From JU2003 Observation}

Sam Chang, Cheryl Klipp, and Giap Huynh

Computational and Information Sciences Directorate, ARL

Ananth Sridhar

Thomas Jefferson High School for Science and Technology

Alexandria, VA 


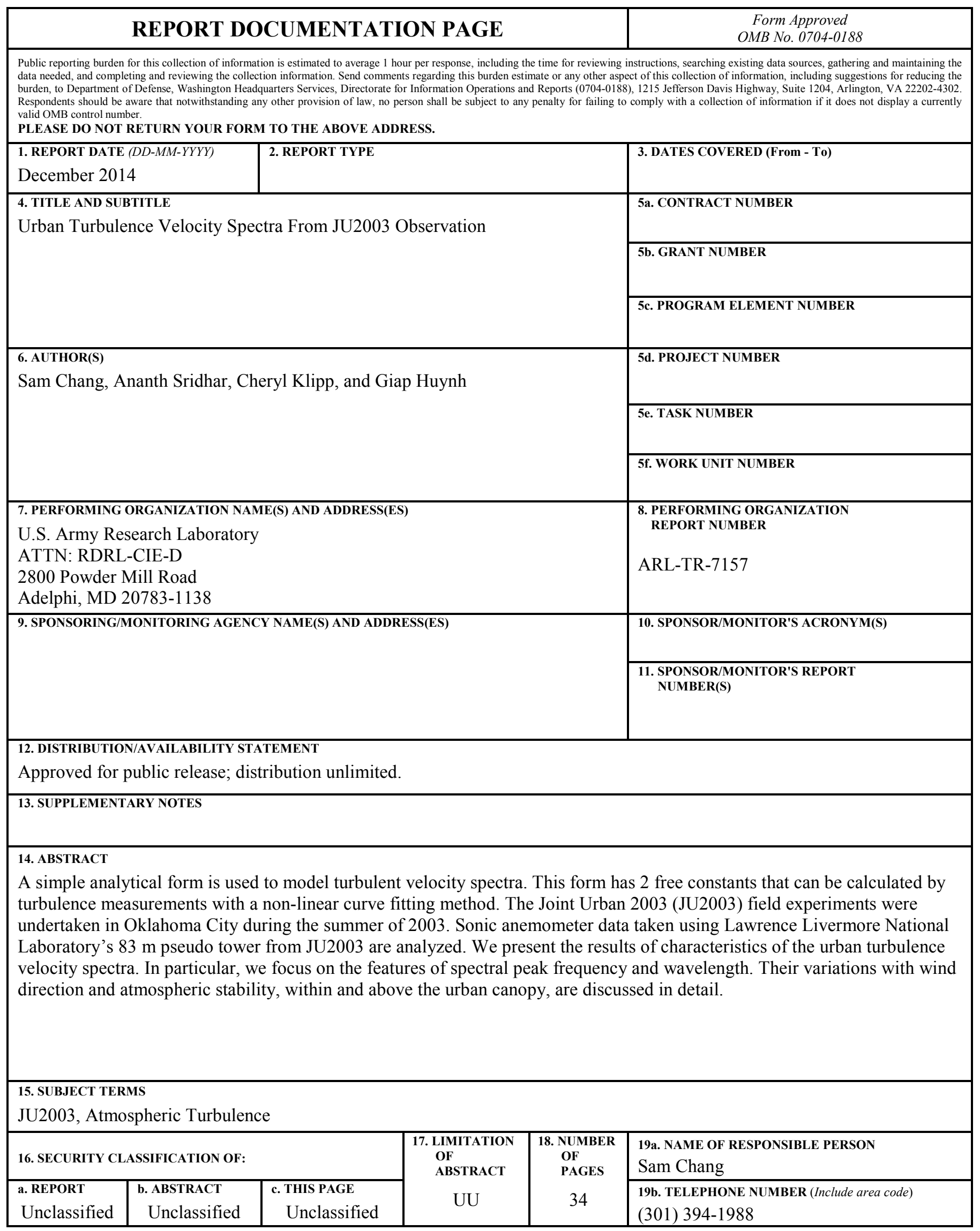




\section{Contents}

List of Figures $\quad$ iv

List of Tables $\quad$ iv

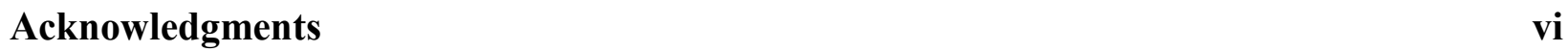

$\begin{array}{ll}\text { 1. Introduction } & 1\end{array}$

2. Model 2

3. Data Analysis $\quad 3$

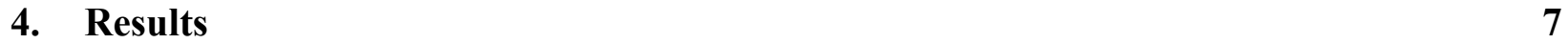

4.1 Urban Canopy Inhomogeneity Effects on Spectral Peaks........................................

4.2 Atmospheric Stability Effects on the Spectral Peaks .................................................. 12

4.3 Observational Height (z) Effects on the Spectral Peaks..........................................19

$\begin{array}{lr}\text { 5. Conclusion } & 22\end{array}$

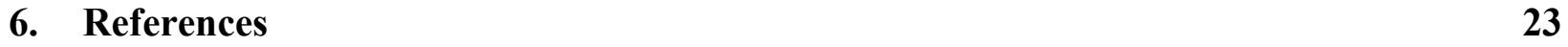

$\begin{array}{ll}\text { Distribution List } & 25\end{array}$ 


\section{List of Figures}

Fig. 1 Building height situation around the LLNL pseudo tower. The upper part shows the variation of building height with distance from the tower for the three $30^{\circ}$ arcs: $135-165^{\circ}$ (right), $165-195^{\circ}$ (middle), and $195-225^{\circ}$ (left), respectively. The lower part shows the variation of building height in the fetch upstream of the tower, presented as function of wind direction. The solid line indicates the maximum building height. The dotted line indicates the mean building height. Courtesy of Lundquist, Shinn and Gouveia (2004).

Fig. 2 An example of the turbulence velocity spectra using the curve fitting of (1). Figure 1a is for $u$, Fig. $1 \mathrm{~b}$ is for $v$, and Fig. $1 \mathrm{c}$ is for $w$. The blue dots are from FFT. The green dots result from averages. The red lines represent the fitted $u, v$, and $w$ spectra of Eq. 1, respectively for a half hour data from level E (42.5 m) on Julian Day 184 (3 July 2003), where $a_{u}=26.40, b_{u}=14.81$ in Fig. 1a, $a_{v}=9.839, b_{v}=7.523$ in Fig. $1 \mathrm{~b}$, and $a_{w}=2.855$, $b_{w}=3.383$ in Fig. 1c. Figure 1d superimposes the fitted spectra for easy comparison.

Fig. 3 Vertical profiles of the mean non-dimensional peak frequencies, $\mathrm{Ni}, i=\mathrm{u}(\mathrm{red}), v$ (green) and $w$ (blue) for the three wind direction sectors: 1) $45^{\circ}<\mathrm{WD}<120^{\circ}$, symbol +; 2) $120^{\circ}<\mathrm{WD}<210^{\circ}$, symbol o; and 3) $210^{\circ}<\mathrm{WD}<315^{\circ}$, symbol *

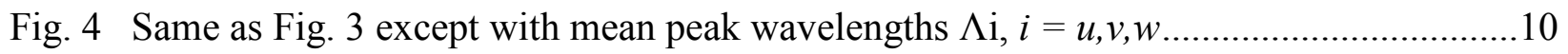

Fig. 5 Vertical profiles of the mean non-dimensional peak frequencies, $\mathrm{Ni}, i=u(\mathrm{red}), v$ (green) and $w$ (blue) for wind direction (WD) sector 2, with respect to the 5 stability categories .....

Fig. 6 Same as Fig. 5 except for the mean peak wavelengths, $\Lambda_{\mathrm{i}}, i=u, v, w$

Fig. 7 Variation of the spectral peaks with the stability $(z / L)$ for $N_{\mathrm{u}}($ Fig. $7 \mathrm{a}), N_{\mathrm{v}}$ (Fig. 7b), and $N_{\mathrm{w}}$ (Fig. 7c) composed from 3 levels (level E,F,G) for $120^{\circ}<\mathrm{WD}<210^{\circ}$. The curves in the Fig. 7 are from the empirical curve fitting, Eq. 12.

Fig. 8 The average spectra of $u, v$, and $w$ at eight levels for the near-neutral conditions

\section{List of Tables}

Table 1 Data situation at 8 levels with respect to the three wind direction (WD) sectors used for present analyses. Number of runs, $z / L(\zeta)$ range, its mean values, and standard deviations $(\sigma)$ are listed for each level.

Table 2 Mean spectral peak frequencies, $\mathrm{Ni}, i=u, v, w$ at 8 levels with respect to three WD sectors, their number of runs $(\#)$, standard deviations $\left(\sigma_{i}\right)$, and corresponding mean peak wavelengths, $\Lambda \mathrm{i}, i=u, v, w$......

Table 3 Impact on the peak frequencies, $\Delta \mathrm{N}_{\mathrm{i}}$, the peak wavelengths, $\Delta \Lambda_{\mathrm{i}}$ and their relative percentage, $\mathrm{R}_{\mathrm{i}(\%)}, i=u, v, w$ due to urban canopy inhomogeneity. 
Table 4 Mean spectral peak frequencies, $N i, i=u, v, w$ at 8 levels with respect to the five stability classes, their number of runs $(\#)$, standard deviations $\left(\sigma_{i}\right)$, and corresponding wavelengths, $\Lambda i, i=u, v, w$

Table 4 Mean spectral peak frequencies, $N i, i=u, v, w$ at 8 levels with respect to the five stability classes, their number of runs $(\#)$, standard deviations $\left(\sigma_{i}\right)$, and corresponding wavelengths, $\Lambda i, i=u, v, w$ (continued)

Table 5 Impact on the peak frequencies, $\Delta \mathrm{N}_{\mathrm{i}}$, the peak wavelengths, $\Delta \Lambda_{\mathrm{i}}$ and their relative percentage, $\mathrm{R}_{\mathrm{i}(\%)}, i=u, v, w$ due to atmospheric stability.......

Table 6 Comparison of relative effects of the wind direction (WD), atmospheric stability $(\mathrm{z} / \mathrm{L})$, and observational height $(\mathrm{z})$ on the $\mathrm{u}-, \mathrm{v}-$, and $\mathrm{w}$-spectral peaks..

Table 7 Mean near-neutral spectral parameters, ai and bi in (1), $i=u, v, w$, their standard deviations $\left(\sigma_{\mathrm{a}}\right.$ and $\left.\sigma_{\mathrm{b}}\right)$, number of runs $(\#)$, corresponding mean peak frequencies $\mathrm{Ni}$, and mean peak wavelengths $\Lambda \mathrm{i}$ 


\section{Acknowledgments}

We thank Dr Julie Lundquist at LLNL for much help, and Dr Adam Wolf with the Department of Ecology and Evolutionary Biology, Princeton University, for his code to calculate co-spectra. We also thank Drs John Noble, Steve Hill, Dennis Garvey, and David Tofsted, and Mr Chatt Williamson at the US Army Research Laboratory (ARL) for having provided help and useful discussion. Mr Dennis Li, a 2009 ARL summer student from Langley High School, had contributed to the development of ARL spectral analyses codes. 


\section{Introduction}

Spectral analyses of turbulent velocity fluctuations in the atmospheric boundary layer over flat terrains have been well studied (Busch and Panofsky, 1968; Panofsky and Dutton, 1984; Kaimal and Finnigan, 1994). However, they are poorly understood over urban areas due to the lack of sufficiently complete measurements of high quality and successful theoretical hypothesis (Feigenwinter, 1999, Roth, 2000). A major field experiment, the Joint Urban 2003 (JU2003) experiment, was a cooperative undertaking to study transport and dispersion in the atmospheric boundary layer in an urban environment. JU2003 was conducted in Oklahoma City in the summer of 2003 (Alwine et al., 2004). The Lawrence Livermore National Laboratory (LLNL) deployed a pseudo-tower of $83 \mathrm{~m}$ height at a downtown site, equipped with sonic anemometers at 8 levels (Lundquist, et al., 2004; Gouveia, et al., 2007). A large amount of sonic anemometer data from the LLNL pseudo-tower were collected, processed, and archived. We have computed and analyzed the turbulence velocity spectra from this data set and present the following results.

Turbulence velocity spectra and co-spectra can provide valuable insights into urban boundary layer structure. There are 2 important aspects that are still unclear and controversial. The first aspect is related to the peak frequency and peak wavelength within and above the urban canopy layer. The second is related to the local isotropy or the transition from anisotropic to isotropic turbulence in the urban boundary layer. This report presents the results for the first aspect. Results related to the second aspect will be presented in a separate paper.

The spectral peak frequency and the peak wavelength are of greater importance to boundary layer meteorologists than the integral length scale since they are representative of the size of the eddies with the most energy, as noted by Kaimal and Finnigan (1994). Previous studies on the spectral peaks for urban canopy flows were interested in 3 issues - the influences of the displacement height (d), the atmospheric stability, and the observation height on those spectral peaks. The results of those previous studies reviewed by Roth (2000) are controversial and uncertain. For example, the composite Fig. 11 in Roth's paper seems uncertain whether the nondimensional spectral peak frequencies for the 3 wind components $(u, v$, and $w)$ increase with increasing height for neutral conditions, although Feigenwinter et al. (1997, 1999) indicated a general increase of non-dimensional peak frequencies with increasing normalized height. On the other hand, the composite Fig. 12 in the same paper appears unclear whether the peak wavelengths for the 3 wind components decrease with increasing stability. Feigenwinter et al. (1999) have shown that the peak frequencies for $u, v$, and $w$ spectra increase with height, but no clear relation of those peaks with atmospheric stability. Chang et al. (2004, 2009, 2010) have reported some new results on the spectral peaks from the JU2003 data. However, they have used only limited data of a few days from that data bank. Our current study presents new results on these 3 issues from the much larger and extensive JU2003 data set. 


\section{Model}

Various analytical expressions have been reviewed and suggested to model turbulent velocity spectra and co-spectra for atmospheric boundary layer (Wilson, 1998, Lee et al. 2004). We use a simple form to model the one-dimensional turbulent velocity $(u, v, w)$ spectra, as suggested by Sorbjan (1989), and Kaimal and Finnigan (1994):

$$
Y=f S_{i}=\frac{a_{i} n}{\left(1+b_{i} n\right)^{\frac{5}{3}}}, \ldots i=u, v, w
$$

where $S_{i}$ is the power spectrum $\left(m^{2} s^{-1}\right)$ for the 3 wind components $i=u, v$, and $w, f$ is the frequency $(\mathrm{Hz}), n=\frac{f z}{\bar{u}}$ is the normalized (non-dimensional) frequency, $z$ is the measurement height (m), and $\bar{u}$ is the mean wind speed at $z . a_{i}$ and $b_{i}$ are empirical constants. These empirical constants can absorb or connote some micrometeorological parameters such as $u_{*}$ (friction velocity) and $L$ (Obukhov length), where

$$
u_{*}=\left(\left(\overline{u^{\prime} w^{\prime}}\right)^{2}+\left(\overline{v^{\prime} w^{\prime}}\right)^{2}\right)^{\frac{1}{4}}
$$

and

$$
L=-\frac{u_{*}^{3} T}{k g \overline{w^{\prime} T \prime}}
$$

where $T$ is the Kelvin temperature, $g$ is the acceleration due to gravity, and $k$ is the Von Karman constant (0.40). The over-bars in these equations denote mean values - half-hour mean values in our data processing. Primes $\left(\mathrm{u}^{\prime}, \mathrm{v}^{\prime}, \mathrm{w}^{\prime}\right.$, and $\left.\mathrm{T}^{\prime}\right)$ denote the deviations from their mean values, respectively.

Given the measured power spectrum from FFT, the experimental constants in Eq. 1 can be evaluated by the standard least square error method. Once the experimental constants $\left(a_{i}\right.$ and $\left.b_{i}\right)$ are determined, the spectral shape and the related spectral peak values can also be calculated as

$$
\begin{aligned}
& N_{i}=\frac{3}{2 b_{i}}, i=u, v, w \\
& \Lambda_{i}=\frac{z}{N_{i}}, i=u, v, w
\end{aligned}
$$

where $N_{i}$ is the normalized peak frequency and $\Lambda_{i}$ is the peak wavelength $(\mathrm{m})$. 


\section{Data Analysis}

Detailed information about the pseudo tower and sonic anemometer data has been provided by Lundquist et al., (2004) and Gouveia et al., (2007). The $83.2 \mathrm{~m}$ pseudo tower was a large cranebased system that provided a stable platform for sonic anemometers. Its location was $35^{\circ} 28.55^{\prime}$ $\mathrm{N}$ and $97^{\circ} 31.07^{\prime} \mathrm{W}$, just north of the central business district of Oklahoma City. The urban canopy of Oklahoma City is highly inhomogeneous. Figure 1 illustrates the building height situation around the tower. Lundquist et al. (2004) have shown the variation of building heights in the fetch upstream of the tower. Although the mean building height varies only slightly, 5-15 $\mathrm{m}$, the maximum height varies considerably. For example, the variation of building height with distance from the tower for the $30^{\circ}\left(165-195^{\circ}\right.$ in meteorological coordinates) arc south of the tower is dramatic, with mean height $12.8 \mathrm{~m}$ and one tall building height $113.5 \mathrm{~m}$, as shown by Fig. 1 .

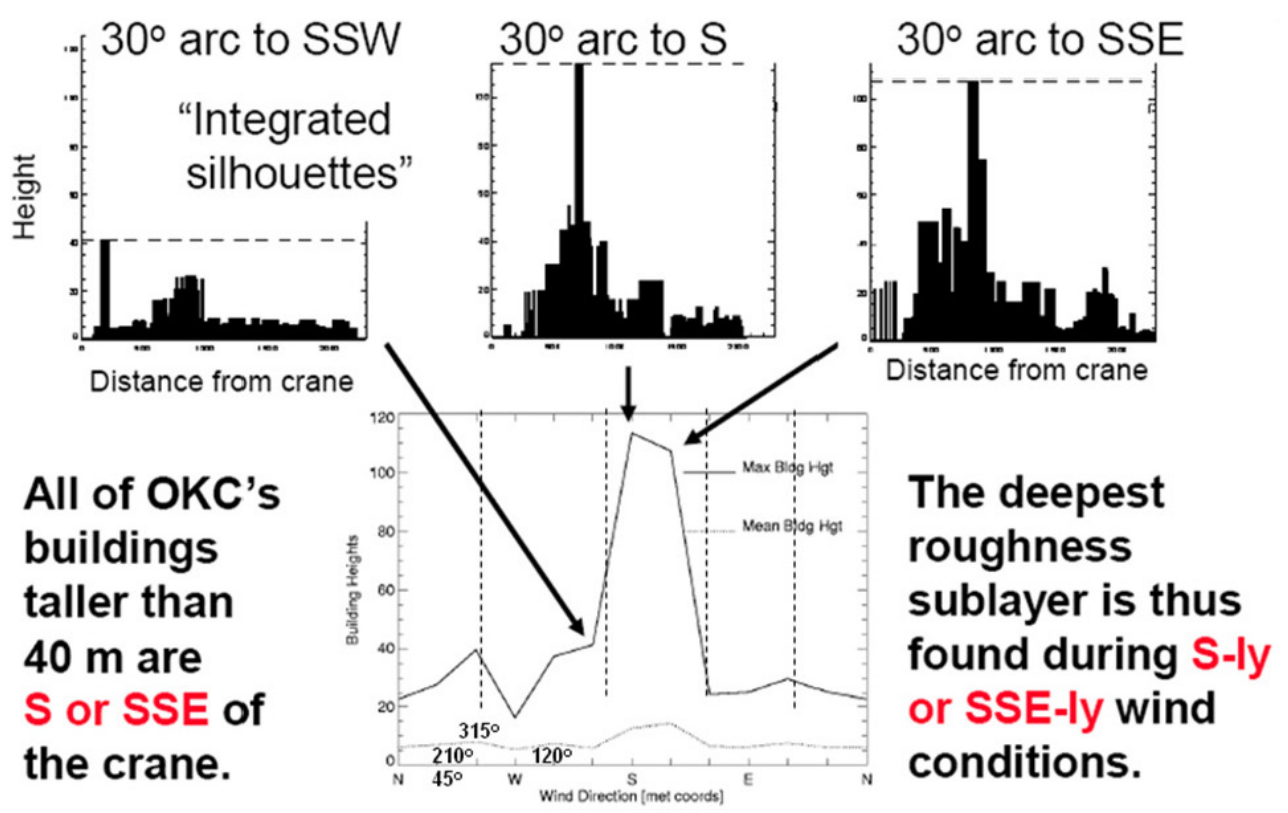

Fig. 1 Building height situation around the LLNL pseudo tower. The upper part shows the variation of building height with distance from the tower for the three $30^{\circ}$ arcs: $135-165^{\circ}$ (right), $165-$ $195^{\circ}$ (middle), and $195-225^{\circ}$ (left), respectively. The lower part shows the variation of building height in the fetch upstream of the tower, presented as function of wind direction. The solid line indicates the maximum building height. The dotted line indicates the mean building height. Courtesy of Lundquist, Shinn and Gouveia (2004).

With the consideration of the building height variation with respect to wind direction (WD), we group the sonic data into 4 WD sectors:

1. $45^{\circ}<\mathrm{WD}<{ }^{\circ} 120^{\circ}$ 
2. $120^{\circ}<\mathrm{WD}<210^{\circ}$

3. $210^{\circ}<\mathrm{WD}<315^{\circ}$

4. $315^{\circ}<\mathrm{WD}<45^{\circ}$

As suggested by Lundquist et al. (2004), the time periods during which the mean wind direction ranged between $315^{\circ}$ and $45^{\circ}$ were not used due to the pseudo tower's 'shadow effect'. The mean building heights in the $3 \mathrm{WD}$ sectors 1,2 , and 3 are estimated as $6.6 \mathrm{~m}, 11.2 \mathrm{~m}$, and $6.8 \mathrm{~m}$, respectively.

Sonic anemometers were mounted on the pseudo-tower at heights of 7.8(A), 14.6(B), 21.5(C), 28.3(D), 42.5(E), 55.8(F), 69.7(G), and 83.2(H) $\mathrm{m}$ above ground level (AGL). The sonic anemometers (R.M. Young model 81000) measured 3 wind components and temperature at a sampling rate of $10 \mathrm{~Hz}$ for 35 days of measurements (from June 28 to August 1, Julian Day 179 to 213,2003 ). The data set has been quality controlled and archived, and is open for public access. For this analysis, 31 days of data (July 1 to July 31) were used. Chang and Huynh (2007) have used several methods to estimate the roughness height $\left(z_{0}\right)$ and the displacement height $(d)$ for the 3 WD sectors. Their values for the 3 WD sectors are approximately

1. $z_{0}=0.93 \mathrm{~m}, d=11.22 \mathrm{~m}$

2. $z_{0}=4.04 \mathrm{~m}, d=19.93 \mathrm{~m}$

3. $z_{0}=0.66 \mathrm{~m}, d=14.65 \mathrm{~m}$

For each day ( $24 \mathrm{~h}$ ) of analysis, data was divided into 48 half-hour segments. This defines a "run" for turbulence analysis. Considering 48 blocks per day over the analysis period yields 1488 runs. However, some questionable data has been excluded. We exclude the data with extremely high or extremely small stability parameter values. The total number of runs is $1061,1100,1157$, 1143, 1161, 1152, 1146, and 1180 for levels A through $\mathrm{H}$, respectively. Table 1 provides data situation at 8 levels with respect to the 3 wind direction sectors used for present analyses.

Table 1 shows the following features for the data used in our analyses. First, the mean values of $\zeta$ $(=\mathrm{z} / \mathrm{L})$ are negative at every level. This indicates that the tower layer was unstable most times in July 2003. Second, the total number of runs for each of the 3 WD sectors at any of the 8 levels exceeds 1000, providing a large sample set for statistics shown in the next section. Finally, more than $70 \%$ of the data is in WD sector 2 . This is primarily due to the prevailing wind direction for Oklahoma City in July 2003. 
Table 1 Data situation at 8 levels with respect to the three wind direction (WD) sectors used for present analyses. Number of runs, $z / L(\zeta)$ range, its mean values, and standard deviations $(\sigma)$ are listed for each level.

\begin{tabular}{|c|c|c|c|c|c|c|c|c|c|}
\hline \multicolumn{2}{|c|}{ WD Sector } & \multirow{2}{*}{196} & \multirow{2}{*}{$\begin{array}{r}\mathbf{2} \\
851 \\
\end{array}$} & \multirow{2}{*}{$\begin{array}{r}3 \\
114 \\
\end{array}$} & \multicolumn{2}{|c|}{ WD Sector } & \multirow{2}{*}{$\begin{array}{r}\mathbf{1} \\
116 \\
\end{array}$} & \multirow{2}{*}{$\begin{array}{r}\mathbf{2} \\
832 \\
\end{array}$} & \multirow{2}{*}{$\begin{array}{r}\mathbf{3} \\
152 \\
\end{array}$} \\
\hline \multirow{5}{*}{$\begin{array}{l}\text { Level A } \\
7.8 \mathrm{~m}\end{array}$} & Run No. & & & & \multirow{5}{*}{$\begin{array}{l}\text { Level B } \\
14.6 \mathrm{~m}\end{array}$} & Run No. & & & \\
\hline & $\operatorname{Min} \zeta$ & -1.39 & -2.33 & -5.32 & & $\operatorname{Min} \zeta$ & -1.85 & -5.74 & -2.16 \\
\hline & $\operatorname{Max} \zeta$ & 0.03 & 0.17 & 0.15 & & $\operatorname{Max} \zeta$ & 0.03 & 0.17 & 0.23 \\
\hline & Mean $\zeta$ & -0.135 & -0.086 & -0.217 & & Mean $\zeta$ & -0.166 & -0.091 & -0.213 \\
\hline & $\sigma$ of $\zeta$ & 0.19 & 0.132 & 0.599 & & $\sigma$ of $\zeta$ & 0.258 & 0.254 & 0.396 \\
\hline \multirow{5}{*}{ Level C $21.5 \mathrm{~m}$} & Run No. & 135 & 816 & 206 & \multirow{5}{*}{$\begin{array}{l}\text { Level D } \\
28.3 \mathrm{~m}\end{array}$} & Run No. & 116 & 842 & 185 \\
\hline & $\operatorname{Min} \zeta$ & -2.61 & -2.40 & -3.53 & & $\operatorname{Min} \zeta$ & -3.21 & -9.52 & -3.76 \\
\hline & $\operatorname{Max} \zeta$ & 0.11 & 0.42 & 0.31 & & $\operatorname{Max} \zeta$ & 0.16 & 0.62 & 0.37 \\
\hline & Mean $\zeta$ & -0.189 & -0.096 & -0.226 & & Mean $\zeta$ & -0.213 & -0.112 & -0.275 \\
\hline & $\sigma$ of $\zeta$ & 0.311 & 0.172 & 0.430 & & $\sigma$ of $\zeta$ & 0.368 & 0.363 & 0.553 \\
\hline \multirow{5}{*}{ Level E 42.5 m } & Run No. & 128 & 871 & 162 & \multirow{5}{*}{$\begin{array}{l}\text { Level F } \\
55.8 \mathrm{~m}\end{array}$} & Run No. & 126 & 835 & 191 \\
\hline & $\operatorname{Min} \zeta$ & -6.60 & -5.27 & -9.22 & & $\operatorname{Min} \zeta$ & -6.56 & -9.15 & -5.90 \\
\hline & $\operatorname{Max} \zeta$ & 0.94 & 0.48 & 1.99 & & $\operatorname{Max} \zeta$ & 1.09 & 1.01 & 1.98 \\
\hline & Mean $\zeta$ & -0.430 & -0.129 & -0.375 & & Mean $\zeta$ & -0.449 & -0.117 & -0.346 \\
\hline & $\sigma$ of $\zeta$ & 0.951 & 0.333 & 1.089 & & $\sigma$ of $\zeta$ & 1.043 & 0.388 & 1.011 \\
\hline \multirow{5}{*}{ Level G 69.7 m } & Run No. & 120 & 859 & 167 & \multirow{5}{*}{$\begin{array}{l}\text { Level H } \\
83.2 \mathrm{~m}\end{array}$} & Run No. & 124 & 862 & 194 \\
\hline & $\operatorname{Min} \zeta$ & -5.24 & -5.15 & -9.80 & & $\operatorname{Min} \zeta$ & -8.28 & -6.58 & -8.30 \\
\hline & $\operatorname{Max} \zeta$ & 3.56 & 1.96 & 3.76 & & $\operatorname{Max} \zeta$ & 5.72 & 2.69 & 4.30 \\
\hline & Mean $\zeta$ & -0.273 & -0.115 & -0.386 & & Mean $\zeta$ & -0.191 & -0.111 & -0.415 \\
\hline & $\sigma$ of $\zeta$ & 1.182 & 0.376 & 1.482 & & $\sigma$ of $\zeta$ & 1.820 & 0.573 & 1.607 \\
\hline
\end{tabular}

Sonic anemometer tilt correction was employed with a 2-angle rotation method (Kaimal and Finnigan, 1994). Computations for tilt correction ran on a block-by-block basis, yielding $u$ (streamwise), $v$ (transverse), and $w$ (vertical) wind components. Turbulent components $u$ ', $v$, and $w$ 'were defined by deviation from a block's mean (Stull, 1988). Turbulence statistics for each block were calculated and used for other analyses.

FFT algorithms used in spectral analysis require input sizes of $2^{\mathrm{n}}$ data points. We use $2^{14}(16384)$ data points —i.e., $1638.4 \mathrm{~s}$ (27'18.4") — of data from each half-hour run (18000 points). The FFT yields $2^{13}=8192$ output data points for each run. Given the $f S_{i}(j)$ for $j=1 \ldots 2^{13}$ from FFT, the squared error is expressed as

$$
\delta^{2}=\sum\left(\left(Y_{j}\right)_{F F T}-\left(Y_{j}\right)_{\text {model }}\right)^{2}, \mathrm{j}=1,2, \ldots \ldots \ldots . .2^{13}
$$

The least squares method is used to determine the 2 parameters $a_{i}$ and $b_{i}$ in Eq. 1 by solving

$$
\frac{\partial\left(\delta^{2}\right)}{\partial a_{i}}=0
$$

and 


$$
\frac{\partial\left(\delta^{2}\right)}{\partial b_{i}}=0
$$

Spectral values $N_{i}$ and $\Lambda_{i}$ can be easily calculated with Eqs. 4 and 5.

Figure 2 shows results obtained from the least-squares method to determine equations for the $u$, $v$, and $w$ spectra. It should be noted that 46 bin averaged points were used instead of the 8192 points from the FFT. This is done to produce a smooth curve in the presence of large fluctuations in high frequencies.
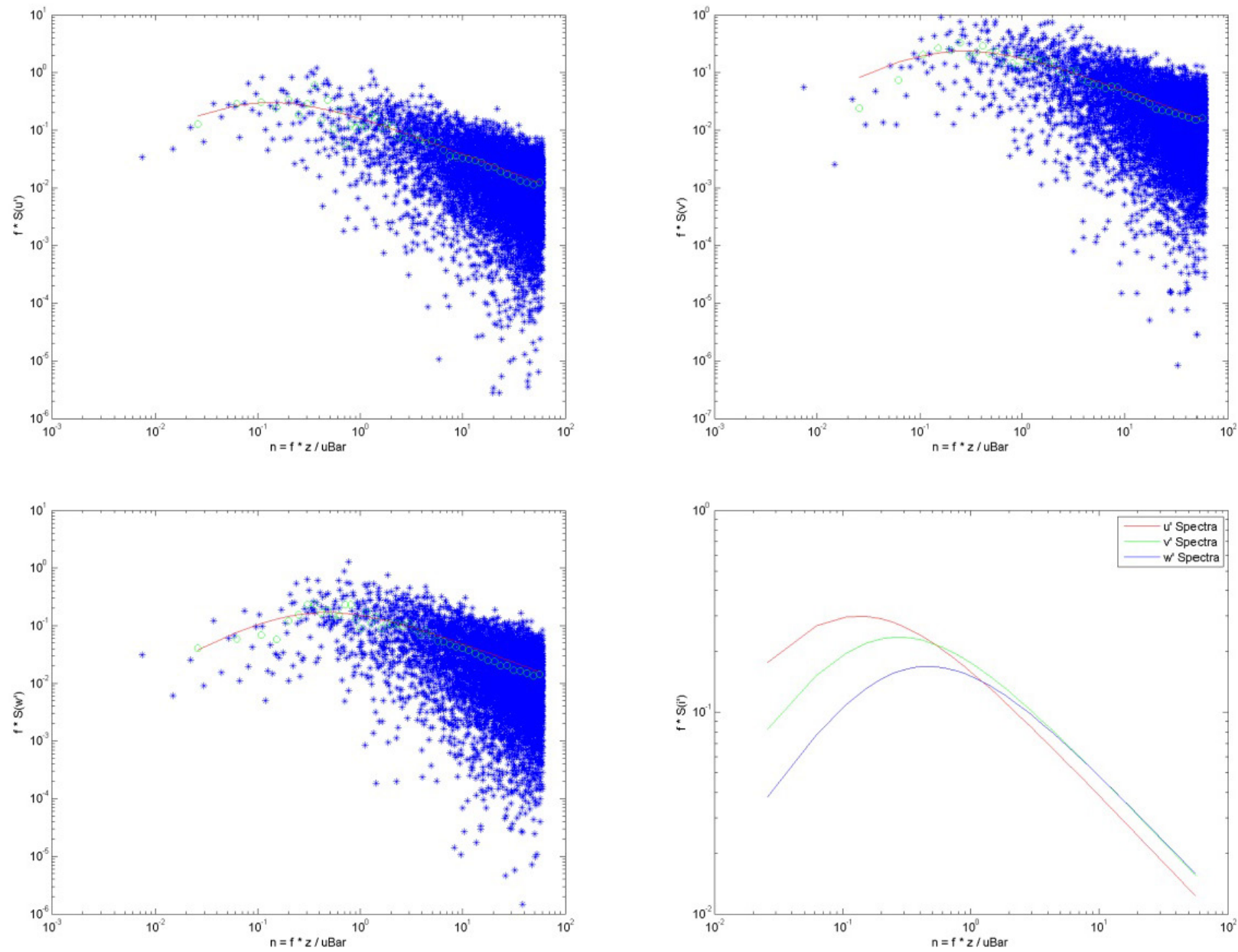

Fig. 2 An example of the turbulence velocity spectra using the curve fitting of (1). Figure 1a is for $u$, Fig. $1 \mathrm{~b}$ is for $v$, and Fig. $1 \mathrm{c}$ is for $w$. The blue dots are from FFT. The green dots result from averages. The red lines represent the fitted $u, v$, and $w$ spectra of Eq. 1, respectively for a half hour data from level $\mathrm{E}(42.5 \mathrm{~m})$ on Julian Day 184 (3 July 2003), where $a_{u}=26.40, b_{u}=14.81$ in Fig. 1a, $a_{v}=9.839, b_{v}=7.523$ in Fig. 1b, and $a_{w}=2.855, b_{w}=3.383$ in Fig. 1c. Figure $1 \mathrm{~d}$ superimposes the fitted spectra for easy comparison. 


\section{Results}

\subsection{Urban Canopy Inhomogeneity Effects on Spectral Peaks}

As noted in the previous section, the urban canopy of Oklahoma City is highly inhomogeneous. As seen from the building height profile (Fig. 1), the urban canopy is very different for the 4 wind direction sectors. The inhomogeneity of Oklahoma City is also manifested in the difference of the roughness parameter $\left(z_{0}\right)$ and the displacement height $(d)$. We will first examine the effects of this inhomogeneity on the spectral peak frequencies by examining the difference of $N_{i}$ with respect to the 3 wind direction sectors used in analysis. Table 2 lists the mean peak frequencies, number of runs, standard deviation, and corresponding mean peak wavelength for the $3 \mathrm{WD}$ sectors. 
Table 2 Mean spectral peak frequencies, $\overline{\mathrm{N}_{\mathrm{i}}}, i=u, v, w$ at 8 levels with respect to three WD sectors, their number of runs $(\#)$, standard deviations $\left(\sigma_{\mathrm{i}}\right)$, and corresponding mean peak wavelengths, $\bar{\Lambda}_{\mathrm{i}}, i=u, v, w$

\begin{tabular}{|c|c|c|c|c|c|c|c|c|c|c|c|c|}
\hline \multicolumn{13}{|c|}{$u$} \\
\hline & \multicolumn{4}{|c|}{ WD Sector $1\left(45^{\circ}-120^{\circ}\right)$} & \multicolumn{4}{|c|}{ WD Sector $2\left(120^{\circ}-210^{\circ}\right)$} & \multicolumn{4}{|c|}{ WD Sector $3\left(210^{\circ}-315^{\circ}\right)$} \\
\hline Level & $\overline{\mathbf{N}_{u}}$ & $\overline{\Lambda_{\mathrm{u}}}(\boldsymbol{m})$ & $\sigma_{u}$ & \# & $\overline{\mathbf{N}_{\mathrm{u}}}$ & $\overline{\Lambda_{\mathrm{u}}}(\mathrm{m})$ & $\sigma_{u}$ & \# & $\overline{\mathbf{N}_{u}}$ & $\overline{\Lambda_{\mathrm{u}}}(\mathrm{m})$ & $\sigma_{u}$ & $\#$ \\
\hline A & 0.0430 & 181.4 & 0.0156 & 55 & 0.0289 & 269.9 & 0.0105 & 843 & 0.0289 & 269.9 & 0.0139 & 103 \\
\hline $\mathrm{B}$ & 0.0557 & 262.1 & 0.0232 & 83 & 0.0461 & 316.7 & 0.0170 & 813 & 0.0416 & 351.0 & 0.0188 & 140 \\
\hline $\mathrm{C}$ & 0.0628 & 342.4 & 0.0289 & 105 & 0.0569 & 377.9 & 0.0222 & 789 & 0.0498 & 431.7 & 0.0236 & 190 \\
\hline $\mathrm{D}$ & 0.0684 & 413.7 & 0.0355 & 99 & 0.0655 & 432.1 & 0.0260 & 805 & 0.0541 & 523.1 & 0.0278 & 166 \\
\hline E & 0.0699 & 608.0 & 0.0431 & 117 & 0.0824 & 515.8 & 0.0350 & 825 & 0.0686 & 619.5 & 0.0425 & 138 \\
\hline $\mathrm{F}$ & 0.0766 & 728.5 & 0.0479 & 102 & 0.0982 & 568.2 & 0.0420 & 783 & 0.0777 & 718.1 & 0.0442 & 160 \\
\hline $\mathrm{G}$ & 0.0924 & 754.3 & 0.0548 & 97 & 0.1127 & 618.5 & 0.0500 & 810 & 0.0929 & 750.3 & 0.0570 & 141 \\
\hline $\mathrm{H}$ & 0.1012 & 822.1 & 0.0633 & 99 & 0.1223 & 680.3 & 0.0561 & 825 & 0.1142 & 728.5 & 0.0683 & 163 \\
\hline \multicolumn{13}{|c|}{$v$} \\
\hline & \multicolumn{4}{|c|}{ WD Sector $1\left(45^{\circ}-120^{\circ}\right)$} & \multicolumn{4}{|c|}{ WD Sector $2\left(120^{\circ}-210^{\circ}\right)$} & \multicolumn{4}{|c|}{ WD Sector $3\left(210^{\circ}-315^{\circ}\right)$} \\
\hline Level & $\overline{\mathbf{N}_{\mathrm{v}}}$ & $\overline{\Lambda_{\mathrm{v}}}(\boldsymbol{m})$ & $\sigma_{v}$ & $\#$ & $\overline{\mathbf{N}_{\mathrm{v}}}$ & $\overline{\Lambda_{\mathrm{v}}}(\boldsymbol{m})$ & $\sigma_{v}$ & $\#$ & $\overline{\mathbf{N}_{\mathrm{v}}}$ & $\overline{\Lambda_{\mathrm{v}}}(\boldsymbol{m})$ & $\sigma_{v}$ & $\#$ \\
\hline $\mathrm{A}$ & 0.0733 & 106.4 & 0.0306 & 56 & 0.0347 & 224.8 & 0.0189 & 816 & 0.0354 & 220.3 & 0.0236 & 90 \\
\hline $\mathrm{B}$ & 0.1312 & 111.3 & 0.0552 & 71 & 0.071 & 186.9 & 0.0398 & 800 & 0.0925 & 157.8 & 0.0549 & 127 \\
\hline $\mathrm{C}$ & 0.1674 & 128.4 & 0.0747 & \begin{tabular}{|l|l}
10 \\
0
\end{tabular} & 0.1138 & 188.9 & 0.0534 & 779 & 0.1248 & 172.3 & 0.0709 & 172 \\
\hline $\mathrm{D}$ & 0.1623 & 174.4 & 0.0873 & 91 & 0.1417 & 199.7 & 0.0660 & 803 & 0.1381 & 204.9 & 0.0794 & 155 \\
\hline E & 0.2235 & 190.2 & 0.1196 & 96 & 0.1958 & 217.1 & 0.0904 & 824 & 0.1668 & 254.8 & 0.1025 & 127 \\
\hline $\mathrm{F}$ & 0.2248 & 248.2 & 0.1503 & 95 & 0.2465 & 226.4 & 0.1127 & 787 & 0.2144 & 260.3 & 0.1310 & 151 \\
\hline G & 0.2601 & 268.0 & 0.1727 & 86 & 0.2926 & 238.2 & 0.1390 & 807 & 0.2595 & 268.0 & 0.1641 & 127 \\
\hline $\mathrm{H}$ & 0.2837 & 293.3 & 0.1902 & 89 & 0.3282 & 253.5 & 0.1563 & 815 & 0.2940 & 283.0 & 0.1949 & 142 \\
\hline \multicolumn{13}{|c|}{$w$} \\
\hline & \multicolumn{4}{|c|}{ WD Sector $1\left(45^{\circ}-120^{\circ}\right)$} & \multicolumn{4}{|c|}{ WD Sector $2\left(120^{\circ}-210^{\circ}\right)$} & \multicolumn{4}{|c|}{ WD Sector $3\left(210^{\circ}-315^{\circ}\right)$} \\
\hline Level & $\overline{\mathbf{N}_{w}}$ & $\overline{\Lambda_{\mathrm{w}(\mathrm{m})}}$ & $\sigma_{w}$ & $\#$ & $\overline{\mathbf{N}_{w}}$ & $\overline{\Lambda_{\mathrm{w}}(\boldsymbol{m})}$ & $\sigma_{w}$ & $\#$ & $\overline{\mathbf{N}_{\mathbf{w}}}$ & $\overline{\Lambda_{\mathrm{w}(\mathrm{m})}}$ & $\sigma_{w}$ & $\#$ \\
\hline A & 0.2440 & 32.0 & 0.0375 & 84 & 0.1990 & 39.2 & 0.0315 & 846 & 0.2258 & 34.5 & 0.0397 & 106 \\
\hline B & 0.3072 & 47.5 & 0.0625 & 96 & 0.2300 & 63.5 & 0.0425 & 826 & 0.2515 & 58.1 & 0.0573 & 148 \\
\hline $\mathrm{C}$ & 0.3464 & 62.1 & 0.0738 & 102 & 0.2638 & 81.5 & 0.0522 & 812 & 0.2888 & 74.5 & 0.0790 & 196 \\
\hline D & 0.3677 & 77.0 & 0.0984 & 93 & 0.2937 & 96.4 & 0.0644 & 837 & 0.3145 & 90.0 & 0.0933 & 166 \\
\hline E & 0.4029 & 105.5 & 0.1352 & 106 & 0.3347 & 127.0 & 0.0847 & 863 & 0.3511 & 121.0 & 0.1430 & 141 \\
\hline $\mathrm{F}$ & 0.3840 & 145.3 & 0.1824 & 104 & 0.3755 & 148.6 & 0.1087 & 823 & 0.3762 & 148.3 & 0.1737 & 169 \\
\hline $\mathrm{G}$ & 0.4258 & 163.7 & 0.2265 & 100 & 0.4346 & 160.4 & 0.1453 & 855 & 0.3892 & 179.1 & 0.2069 & 141 \\
\hline $\mathrm{H}$ & 0.4858 & 171.3 & 0.3195 & 108 & 0.5074 & 164.0 & 0.1849 & 859 & 0.4539 & 183.3 & 0.2817 & 173 \\
\hline
\end{tabular}


Based on Table 2, Figs. 3 and 4 show the vertical profiles of the mean non-dimensional peak frequencies $\left(\overline{\mathrm{N}_{i}}, i=u, v, w\right)$ and mean peak wavelengths $\left(\overline{\Lambda_{\mathrm{i}}}, i=u, v, w\right)$ for the $3 \mathrm{WD}$ sectors.

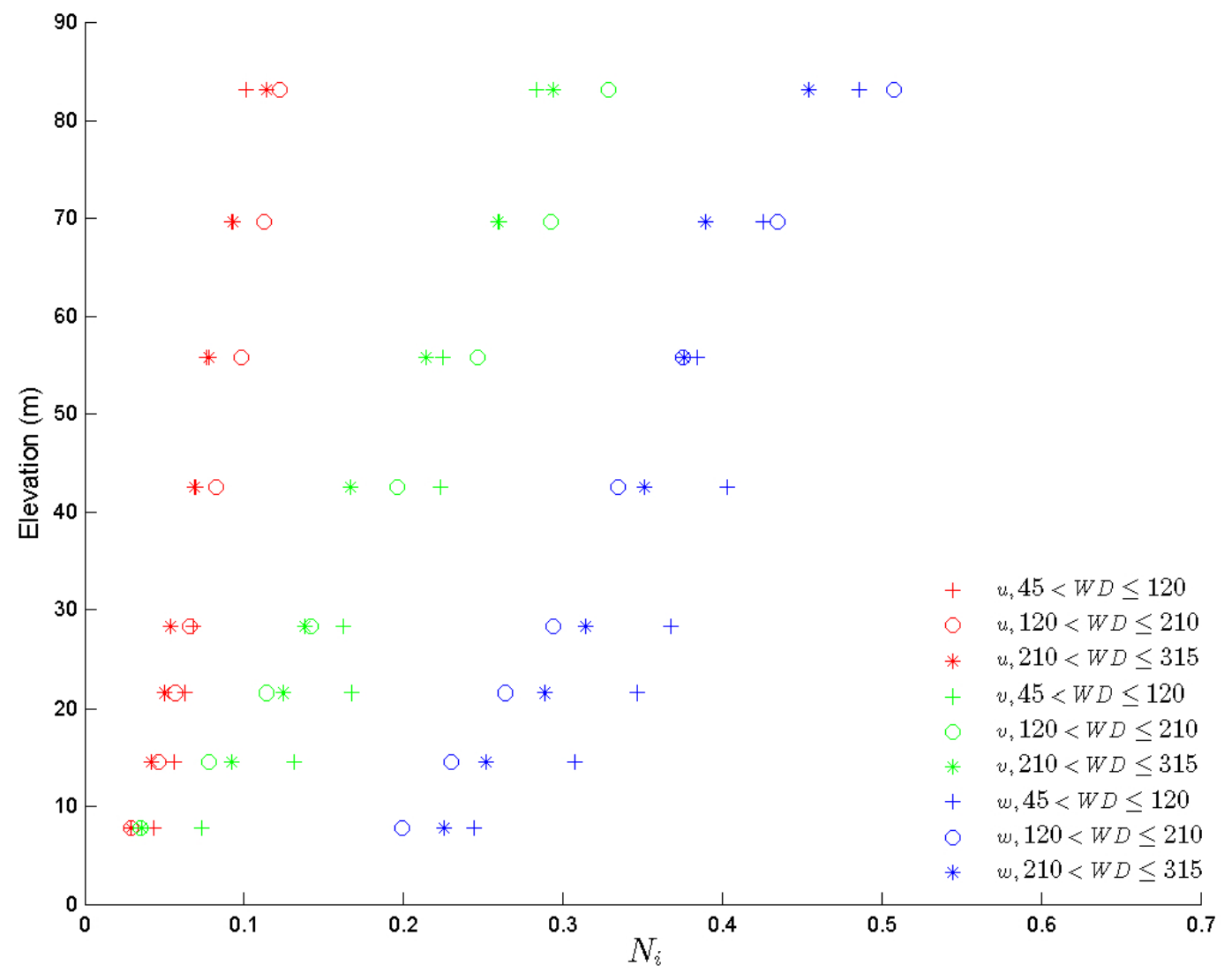

Fig. 3 Vertical profiles of the mean non-dimensional peak frequencies, $\overline{\mathrm{N}}_{\mathrm{i}}, i=\mathrm{u}($ red), $v$ (green) and $w$ (blue) for the three wind direction sectors: 1) $45^{\circ}<\mathrm{WD}<120^{\circ}$, symbol + ; 2) $120^{\circ}<\mathrm{WD}<210^{\circ}$, symbol o; and 3) $210^{\circ}<\mathrm{WD}<315^{\circ}$, symbol * 


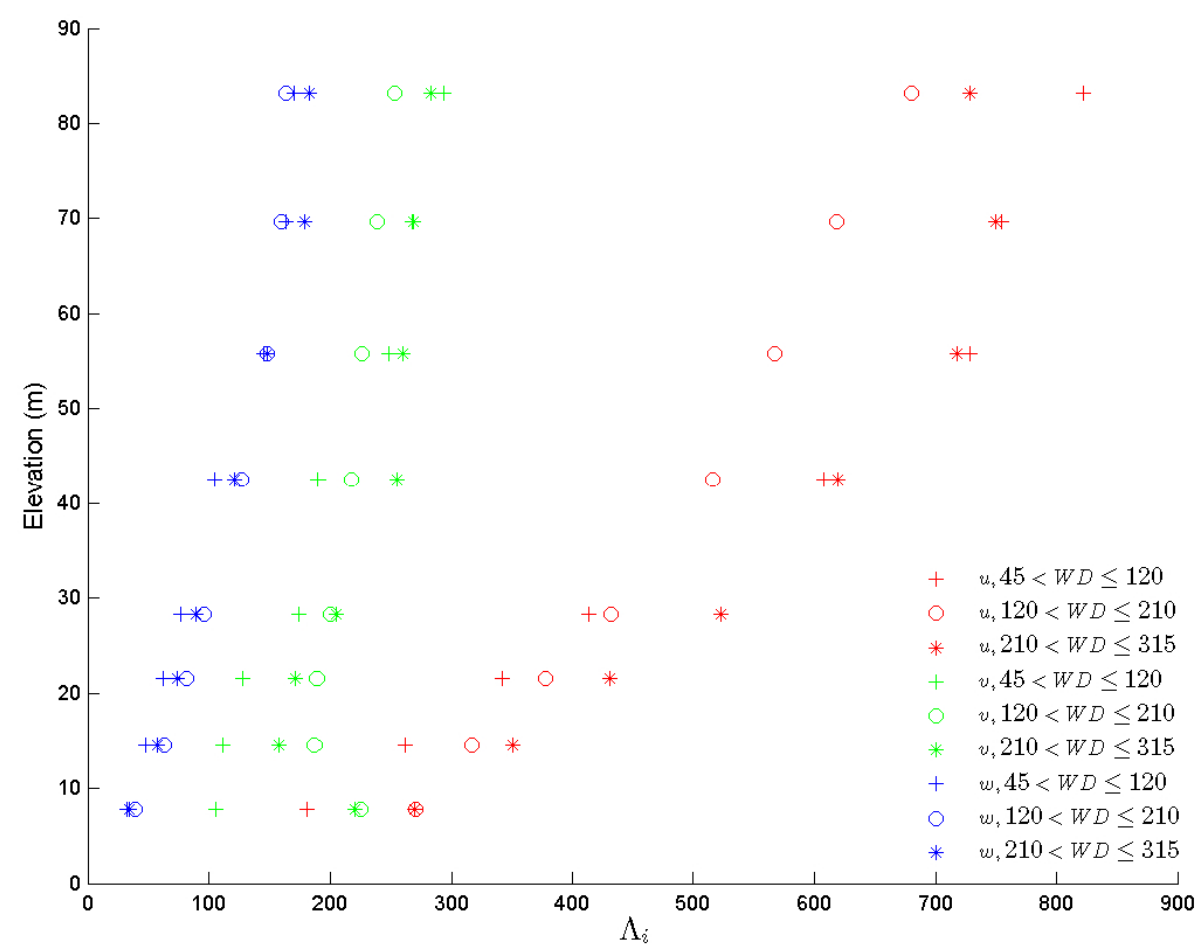

Fig. 4 Same as Fig. 3 except with mean peak wavelengths $\overline{\Lambda_{\mathrm{i}}}, i=u, v, w$

The data in Table 2 and on Figs. 3 and 4 show the general features for the mean values of the non-dimensional peak frequency $\bar{N}_{i}$ and peak wavelengths $\bar{\Lambda}_{\mathrm{i}}$ for the $3 \mathrm{WD}$ sectors as follows:

1. $\bar{N}_{i}$ increases with height from level A $(7.8 \mathrm{~m})$ to level $\mathrm{H}(83.2 \mathrm{~m})$, as shown in Fig. 3. For example, $\bar{N}_{u}$ increases from 0.0289 to $0.1233, \bar{N}_{v}$ from 0.0347 to 0.3282 , and $\bar{N}_{w}$ from 0.1990 to 0.5074 for $\mathrm{WD}(2)$

2. Likewise, $\overline{\Lambda_{\mathrm{i}}}$ increases with height from level A to level H. $\overline{\Lambda_{\mathrm{u}}}$ increases from $269.9 \mathrm{~m}$ to $680.3 \mathrm{~m}, \overline{\Lambda_{\mathrm{v}}}$ increases from $224.8 \mathrm{~m}$ to $253.5 \mathrm{~m}$, and $\overline{\Lambda_{\mathrm{w}}}$ from $39.2 \mathrm{~m}$ to $164.0 \mathrm{~m}$ for $\mathrm{WD}(2)$.

3. At the same level, there exists

$$
\frac{\bar{N}_{u}<\bar{N}_{v}<\bar{N}_{w}}{\Lambda_{\mathrm{u}}}>\overline{\Lambda_{\mathrm{v}}}>\overline{\Lambda_{\mathrm{w}}}
$$

For a further analysis of the impact of the inhomogeneity on the spectral peaks, we can define 3 indices for a certain level as follows

$$
\begin{gathered}
\Delta N_{i}=\left(\bar{N}_{i}\right)_{\max }-\left(\bar{N}_{i}\right)_{\min } \\
\Delta \Lambda_{i}=\left(\bar{\Lambda}_{i}\right)_{\max }-\left(\bar{\Lambda}_{i}\right)_{\min } \\
R_{i}=\frac{\Delta N_{i}}{0.5\left[\left(\bar{N}_{i}\right)_{\max }+\left(\bar{N}_{i}\right) \min \right]} * 100
\end{gathered}
$$


where the subscripts $\max$ and $\min$ indicate the maximum and minimum values of the 3 wind direction sectors at each instrument level. $\Delta N_{i}, \Delta \Lambda_{i}$, and $R_{i}$ values are presented in Table 3 .

Table 3 Impact on the peak frequencies, $\Delta \mathrm{N}_{\mathrm{i}}$, the peak wavelengths, $\Delta \Lambda_{\mathrm{i}}$ and their relative percentage, $\mathrm{R}_{\mathrm{i}(\%)}, i=$ $u, v, w$ due to urban canopy inhomogeneity

\begin{tabular}{|c|c|c|c|c|}
\hline & & $\mathbf{u}$ & $\mathbf{v}$ & $\mathbf{w}$ \\
\hline \multirow{3}{*}{ A } & $\Delta N_{i}$ & 0.0141 & 0.0386 & 0.0450 \\
\hline & $\Delta \Lambda_{i}$ & 88.5 & 118.4 & 7.23 \\
\hline & $R_{i(\%)}$ & 39.2 & 71.5 & 20.3 \\
\hline \multirow{3}{*}{ B } & $\Delta N_{i}$ & 0.0141 & 0.0531 & 0.0772 \\
\hline & $\Delta \Lambda_{i}$ & 88.9 & 75.7 & 16.0 \\
\hline & $R_{i(\%)}$ & 29.0 & 59.5 & 28.7 \\
\hline \multirow{3}{*}{$\mathrm{C}$} & $\Delta N_{i}$ & 0.130 & 0.0536 & 0.0826 \\
\hline & $\Delta \Lambda_{i}$ & 89.3 & 60.5 & 19.4 \\
\hline & $R_{i(\%)}$ & 23.1 & 38.1 & 27.1 \\
\hline \multirow{3}{*}{ D } & $\Delta N_{i}$ & 0.143 & 0.0242 & 0.0740 \\
\hline & $\Delta \Lambda_{i}$ & 109.4 & 30.5 & 19.4 \\
\hline & $R_{i(\%)}$ & 23.4 & 32.2 & 22.4 \\
\hline \multirow{3}{*}{ E } & $\Delta N_{i}$ & 0.0138 & 0.0567 & 0.0682 \\
\hline & $\Delta \Lambda_{i}$ & 103.7 & 64.6 & 21.5 \\
\hline & $R_{i(\%)}$ & 18.3 & 29.1 & 18.5 \\
\hline \multirow{3}{*}{$\mathrm{F}$} & $\Delta N_{i}$ & 0.0216 & 0.0321 & 0.0085 \\
\hline & $\Delta \Lambda_{i}$ & 160.3 & 33.9 & 3.3 \\
\hline & $R_{i(\%)}$ & 24.7 & 13.9 & 2.2 \\
\hline \multirow{3}{*}{ G } & $\Delta N_{i}$ & 0.0203 & 0.0331 & 0.0454 \\
\hline & $\Delta \Lambda_{i}$ & 135.8 & 30.4 & 18.7 \\
\hline & $R_{i(\%)}$ & 19.8 & 12.0 & 11.0 \\
\hline \multirow{3}{*}{$\mathrm{H}$} & $\Delta N_{i}$ & 0.0211 & 0.0445 & 0.0535 \\
\hline & $\Delta \Lambda_{i}$ & 141.8 & 39.8 & 19.3 \\
\hline & $R_{i(\%)}$ & 18.9 & 14.5 & 11.1 \\
\hline \multirow{3}{*}{ Average } & $\Delta N_{i}$ & 0.0165 & 0.0420 & 0.0568 \\
\hline & $\Delta \Lambda_{i}$ & 114.7 & 56.7 & 15.6 \\
\hline & $R_{i(\%)}$ & 24.5 & 33.9 & 17.7 \\
\hline
\end{tabular}

Table 3 implies that the urban canopy inhomogeneity can induce an average of $16-25 \%$ variation in spectral peaks both in the mean peak frequencies and mean peak wavelengths. In the lower levels (roughness sublayer), it has the largest impact on $N_{v}$, and in the upper levels it has the largest impact on $N_{u}$. Its impact on $N_{w}$ is smaller than that on $N_{u}$ or $N_{v}$. At level A, the impact is very significant. It should also be noted that large changes in $N_{i}$ and $\Lambda_{i}$ in the lowest level occur between $\mathrm{WD}(1)$ and $\mathrm{WD}(3)$. The difference of mean building height and the roughness length between those $2 \mathrm{WD}$ sectors are only $0.2 \mathrm{~m}$ and $0.23 \mathrm{~m}$, respectively. Therefore, it is difficult to 
explain the variations in the spectral peaks by either the mean building height or roughness layer changes.

\subsection{Atmospheric Stability Effects on the Spectral Peaks}

Several parameters can be used to define atmospheric stability for the atmospheric boundary layer (Stull, 1988). Although $\frac{z-d}{L}$ has been used by many authors, we choose to use $\zeta=\frac{z}{L}$ to express the stability where $z$ is the height above the ground, and $L$ is the Obukhov length, since $d$ (the displacement height) is not well-defined for inhomogeneous canopy flow. We have divided the stability $\zeta$ into 5 classes:

1. Very unstable $\quad-10.0<\zeta \leq-0.20$

2. Unstable $\quad-0.20<\zeta \leq-0.10$

3. Near Neutral $\quad-0.10<\zeta \leq 0.10$

4. Stable $\quad 0.10<\zeta \leq 0.20$

5. Very Stable $\quad 0.20<\zeta \leq 10.0$

There are very few data points with either $\frac{z}{L}$ smaller than -10.0 or larger than 10.0 that seem unreliable and are, therefore, excluded in our analysis.

Table 4 lists the mean values of the spectral peaks $\overline{\mathrm{N}_{\mathrm{i}}}, i=u, v, w$ at 8 levels with respect to 5 stability classes, their number of runs (\#), standard deviations $\sigma_{i}$, and corresponding mean values of peak wavelengths $\overline{\Lambda_{\mathrm{i}}}, i=u, v, w$. The number of runs (\#) has a large difference between the 5 stability classes. The near-neutral class has the most data, between 386 and 617 for different levels, and the very stable class has the least data, with no more than 66 samples. In the lower levels there was no very stable case and very few stable cases, which may be related to the urban heat island. The standard deviations appear to increase with height. 
Table 4 Mean spectral peak frequencies, $\bar{N}_{i}, i=u, v, w$ at 8 levels with respect to the five stability classes, their number of runs (\#), standard deviations $\left(\sigma_{\mathrm{i}}\right)$, and corresponding wavelengths, $\bar{\Lambda}_{i}, i=u, v, w$

\begin{tabular}{|c|c|c|c|c|c|c|c|c|c|c|c|c|}
\hline \multicolumn{13}{|c|}{ Very Unstable $(-10.0<\zeta<-0.2)$} \\
\hline & $\overline{N_{u}}$ & \# & $\sigma_{u}$ & $\overline{\Lambda_{u}}$ & $\overline{N_{v}}$ & \# & $\sigma_{u}$ & $\overline{\Lambda_{v}}$ & $\overline{N_{w}}$ & \# & $\sigma_{w}$ & $\overline{\Lambda_{w}}$ \\
\hline A & 0.0217 & 58 & 0.0116 & 359.4 & 0.017 & 52 & 0.0092 & 458.8 & 0.2026 & 63 & 0.0368 & 38.5 \\
\hline $\mathrm{B}$ & 0.0352 & 56 & 0.0182 & 414.8 & 0.0341 & 51 & 0.0246 & 428.2 & 0.227 & 63 & 0.0544 & 64.32 \\
\hline $\mathrm{C}$ & 0.0446 & 77 & 0.0212 & 482.1 & 0.0495 & 64 & 0.0275 & 434.3 & 0.2346 & 80 & 0.0514 & 91.65 \\
\hline $\mathrm{D}$ & 0.0466 & 101 & 0.0235 & 607.3 & 0.0668 & 85 & 0.0401 & 423.7 & 0.2472 & 107 & 0.0597 & 114.5 \\
\hline $\mathrm{E}$ & 0.0549 & 152 & 0.0271 & 774.1 & 0.0985 & 131 & 0.0667 & 431.5 & 0.2647 & 161 & 0.0736 & 160.6 \\
\hline $\mathrm{F}$ & 0.0683 & 151 & 0.037 & 817 & 0.1185 & 137 & 0.0729 & 470.9 & 0.2756 & 168 & 0.0778 & 202.5 \\
\hline $\mathrm{G}$ & 0.0777 & 173 & 0.0409 & 897 & 0.135 & 158 & 0.0786 & 516.3 & 0.3012 & 196 & 0.1014 & 231.4 \\
\hline $\mathrm{H}$ & 0.0832 & 199 & 0.0489 & 1000 & 0.1513 & 184 & 0.079 & 549.9 & 0.3335 & 219 & 0.1194 & 249.5 \\
\hline \multicolumn{13}{|c|}{ Unstable $(-\mathbf{0 . 2}<\zeta<\mathbf{- 0 . 1})$} \\
\hline & $\overline{N_{u}}$ & $\#$ & $\sigma_{u}$ & $\overline{\Lambda_{u}}$ & $\overline{N_{v}}$ & $\#$ & $\sigma_{u}$ & $\overline{\Lambda_{v}}$ & $\overline{N_{w}}$ & $\#$ & $\sigma_{w}$ & $\overline{\Lambda_{w}}$ \\
\hline A & 0.0256 & 166 & 0.0102 & 304.7 & 0.0222 & 157 & 0.0131 & 351.4 & 0.195 & 167 & 0.029 & 40 \\
\hline B & 0.0401 & 158 & 0.0146 & 364.1 & 0.0455 & 148 & 0.0266 & 320.9 & 0.2157 & 157 & 0.0373 & 67.69 \\
\hline $\mathrm{C}$ & 0.0497 & 163 & 0.0212 & 432.6 & 0.0768 & 155 & 0.0438 & 279.9 & 0.2498 & 166 & 0.049 & 86.07 \\
\hline $\mathrm{D}$ & 0.0548 & 166 & 0.024 & 516.4 & 0.0921 & 166 & 0.0481 & 307.3 & 0.2685 & 170 & 0.0583 & 105.4 \\
\hline $\mathrm{E}$ & 0.0684 & 187 & 0.0272 & 621.3 & 0.137 & 187 & 0.0658 & 310.2 & 0.3005 & 191 & 0.0589 & 141.4 \\
\hline $\mathrm{F}$ & 0.08 & 172 & 0.0349 & 697.5 & 0.1786 & 167 & 0.0739 & 312.4 & 0.3269 & 174 & 0.071 & 170.7 \\
\hline $\mathrm{G}$ & 0.0869 & 167 & 0.0387 & 802.1 & 0.2106 & 165 & 0.0783 & 331 & 0.3689 & 169 & 0.0789 & 188.9 \\
\hline $\mathrm{H}$ & 0.0866 & 148 & 0.0382 & 960.7 & 0.2393 & 152 & 0.084 & 347.7 & 0.424 & 153 & 0.093 & 196.2 \\
\hline \multicolumn{13}{|c|}{ Near-Neutral $(-0.1<\zeta<0.1)$} \\
\hline & $\overline{N_{u}}$ & $\#$ & $\sigma_{u}$ & $\overline{\Lambda_{u}}$ & $\overline{N_{v}}$ & $\#$ & $\sigma_{u}$ & $\overline{\Lambda_{v}}$ & $\overline{N_{w}}$ & $\#$ & $\sigma_{w}$ & $\overline{\Lambda_{w}}$ \\
\hline $\mathrm{A}$ & 0.0304 & 617 & 0.0100 & 256.6 & 0.0394 & 605 & 0.0184 & 198.0 & 0.1996 & 614 & 0.0312 & 39.08 \\
\hline $\mathrm{B}$ & 0.0486 & 598 & 0.0166 & 300.4 & 0.0899 & 600 & 0.0363 & 162.4 & 0.2339 & 605 & 0.0416 & 62.42 \\
\hline $\mathrm{C}$ & 0.0607 & 548 & 0.0214 & 354.2 & 0.1311 & 558 & 0.0467 & 164.0 & 0.2714 & 563 & 0.0503 & 79.22 \\
\hline $\mathrm{D}$ & 0.0722 & 535 & 0.024 & 392.0 & 0.1672 & 546 & 0.0548 & 169.3 & 0.3086 & 554 & 0.0585 & 91.70 \\
\hline E & 0.0951 & 469 & 0.032 & 464.9 & 0.2387 & 480 & 0.0657 & 178 & 0.3633 & 486 & 0.0710 & 117.0 \\
\hline $\mathrm{F}$ & 0.1114 & 414 & 0.0357 & 500.9 & 0.2998 & 435 & 0.0831 & 186.1 & 0.4147 & 434 & 0.0866 & 134.6 \\
\hline $\mathrm{G}$ & 0.1289 & 402 & 0.0421 & 540.7 & 0.3584 & 415 & 0.1026 & 194.5 & 0.4812 & 420 & 0.1042 & 144.8 \\
\hline $\mathrm{H}$ & 0.1425 & 386 & 0.0436 & 583.9 & 0.4037 & 387 & 0.1034 & 206.1 & 0.5712 & 389 & 0.1268 & 145.7 \\
\hline
\end{tabular}


Table 4 Mean spectral peak frequencies, $\bar{N}_{i}, i=u, v, w$ at 8 levels with respect to the five stability classes, their number of runs (\#), standard deviations $\left(\sigma_{\mathrm{i}}\right)$, and corresponding wavelengths, $\bar{\Lambda}_{i}, i=u, v, w$ (continued)

\begin{tabular}{|c|c|c|c|c|c|c|c|c|c|c|c|c|}
\hline \multicolumn{13}{|c|}{ Stable $(0.1<\zeta<0.2)$} \\
\hline & $\overline{N_{u}}$ & $\#$ & $\sigma_{u}$ & $\overline{\Lambda_{u}}$ & $\overline{N_{v}}$ & $\#$ & $\sigma_{u}$ & $\overline{A_{v}}$ & $\overline{N_{w}}$ & $\#$ & $\sigma_{w}$ & $\overline{\Lambda_{w}}$ \\
\hline A & 0.0408 & 2 & 0.0057 & 191.2 & 0.0482 & 2 & 0.0292 & 161.8 & 0.2127 & 2 & 0.1221 & 36.67 \\
\hline $\mathrm{B}$ & 0.0674 & 1 & 0 & 216.6 & 0.1126 & 1 & 0 & 129.7 & 0.2884 & 1 & 0 & 50.62 \\
\hline $\mathrm{C}$ & 0.0914 & 1 & 0 & 235.2 & 0.2284 & 1 & 0 & 94.1 & 0.3702 & 2 & 0.0292 & 58.08 \\
\hline $\mathrm{D}$ & 0.1043 & 3 & 0.0278 & 271.3 & 0.27 & 5 & 0.0592 & 104.8 & 0.4456 & 5 & 0.0390 & 63.51 \\
\hline $\mathrm{E}$ & 0.1368 & 11 & 0.025 & 310.7 & 0.2993 & 16 & 0.0605 & 142 & 0.4803 & 16 & 0.0976 & 88.49 \\
\hline $\mathrm{F}$ & 0.1473 & 25 & 0.0383 & 378.8 & 0.3706 & 26 & 0.0877 & 150.6 & 0.5411 & 26 & 0.0828 & 103.1 \\
\hline G & 0.1611 & 27 & 0.0436 & 432.7 & 0.4582 & 29 & 0.0898 & 152.1 & 0.6763 & 29 & 0.0982 & 103.1 \\
\hline $\mathrm{H}$ & 0.1731 & 32 & 0.0392 & 480.6 & 0.546 & 31 & 0.0939 & 152.4 & 0.7468 & 32 & 0.1276 & 111.4 \\
\hline \multicolumn{13}{|c|}{ Very Stable $(0.2<\zeta<\mathbf{1 0 . 0})$} \\
\hline & $\overline{N_{u}}$ & $\#$ & $\sigma_{u}$ & $\overline{\Lambda_{u}}$ & $\overline{N_{v}}$ & \# & $\sigma_{u}$ & $\overline{\Lambda_{v}}$ & $\overline{N_{w}}$ & $\#$ & $\sigma_{w}$ & $\overline{\Lambda_{w}}$ \\
\hline A & 0 & 0 & 0 & & 0 & 0 & 0 & & 0 & 0 & 0 & \\
\hline $\mathrm{B}$ & 0 & 0 & 0 & & 0 & 0 & 0 & & 0 & 0 & 0 & \\
\hline $\mathrm{C}$ & 0 & 0 & 0 & & 0.1825 & 1 & 0 & 117.8 & 0.4298 & 1 & 0 & 50.02 \\
\hline $\mathrm{D}$ & 0 & 0 & 0 & & 0.1849 & 1 & 0 & 153.1 & 0.4949 & 1 & 0 & 57.18 \\
\hline $\mathrm{E}$ & 0.1201 & 6 & 0.0359 & 353.8 & 0.3476 & 10 & 0.0755 & 122.3 & 0.5163 & 9 & 0.0473 & 82.32 \\
\hline $\mathrm{F}$ & 0.1449 & 21 & 0.0407 & 385.1 & 0.3568 & 22 & 0.1084 & 156.4 & 0.5633 & 21 & 0.1011 & 99.06 \\
\hline $\mathrm{G}$ & 0.1749 & 41 & 0.0435 & 398.5 & 0.4494 & 40 & 0.1010 & 155.1 & 0.6954 & 41 & 0.1181 & 100.2 \\
\hline $\mathrm{H}$ & 0.1838 & 60 & 0.0590 & 452.7 & 0.4939 & 61 & 0.1287 & 168.5 & 0.7860 & 66 & 0.1723 & 105.9 \\
\hline
\end{tabular}

Based on Table 4, Figs. 5 and 6 show the vertical profiles of the mean non-dimensional peak frequencies $\overline{N_{i}}$ and mean peak wavelengths $\overline{\Lambda_{i}}$ for the 5 stability classes. 


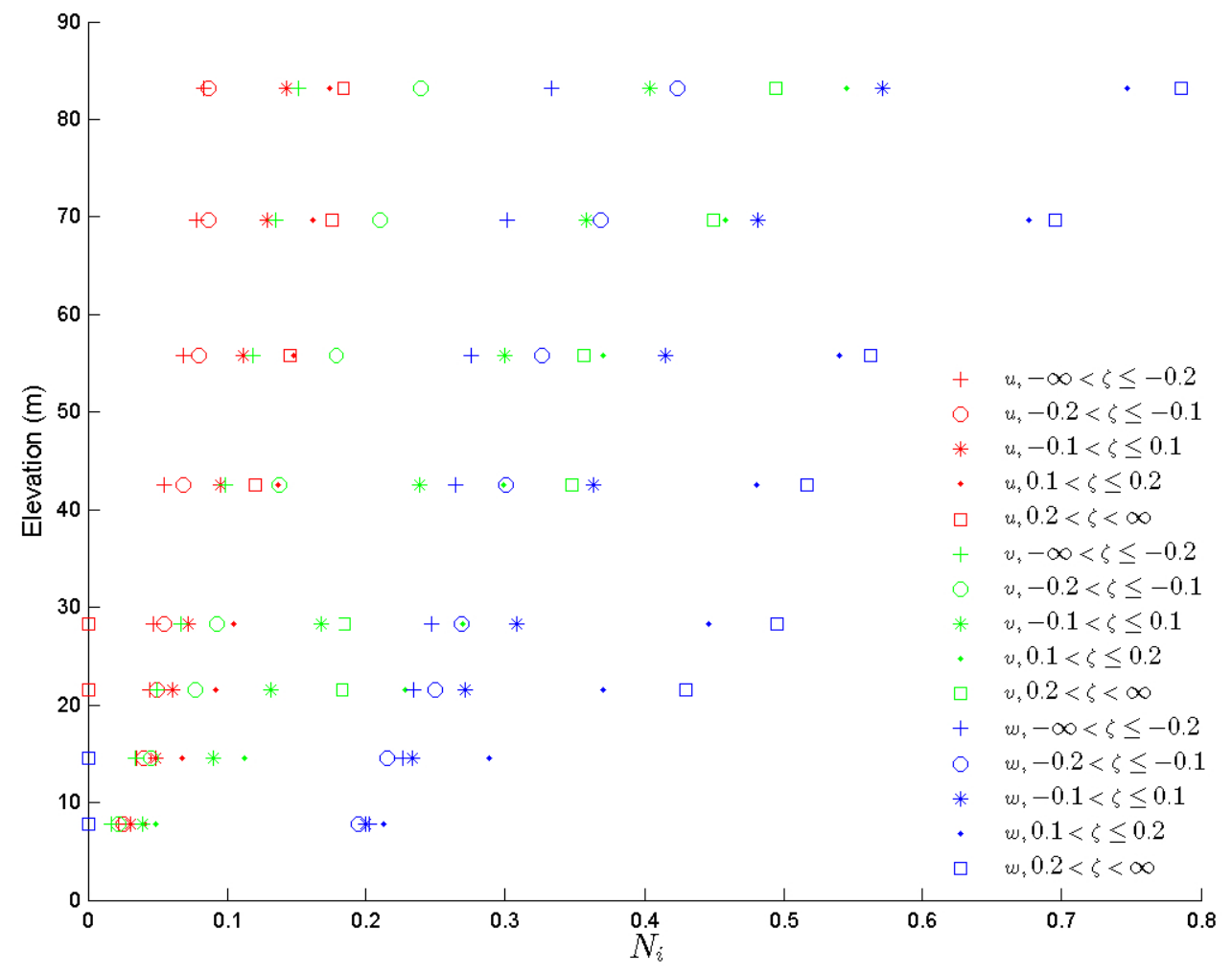

Fig. 5 Vertical profiles of the mean non-dimensional peak frequencies, $\overline{\mathrm{N}}_{\mathrm{i}}, i=u$ (red), $v$ (green) and $w$ (blue) for wind direction (WD) sector 2, with respect to the 5 stability categories

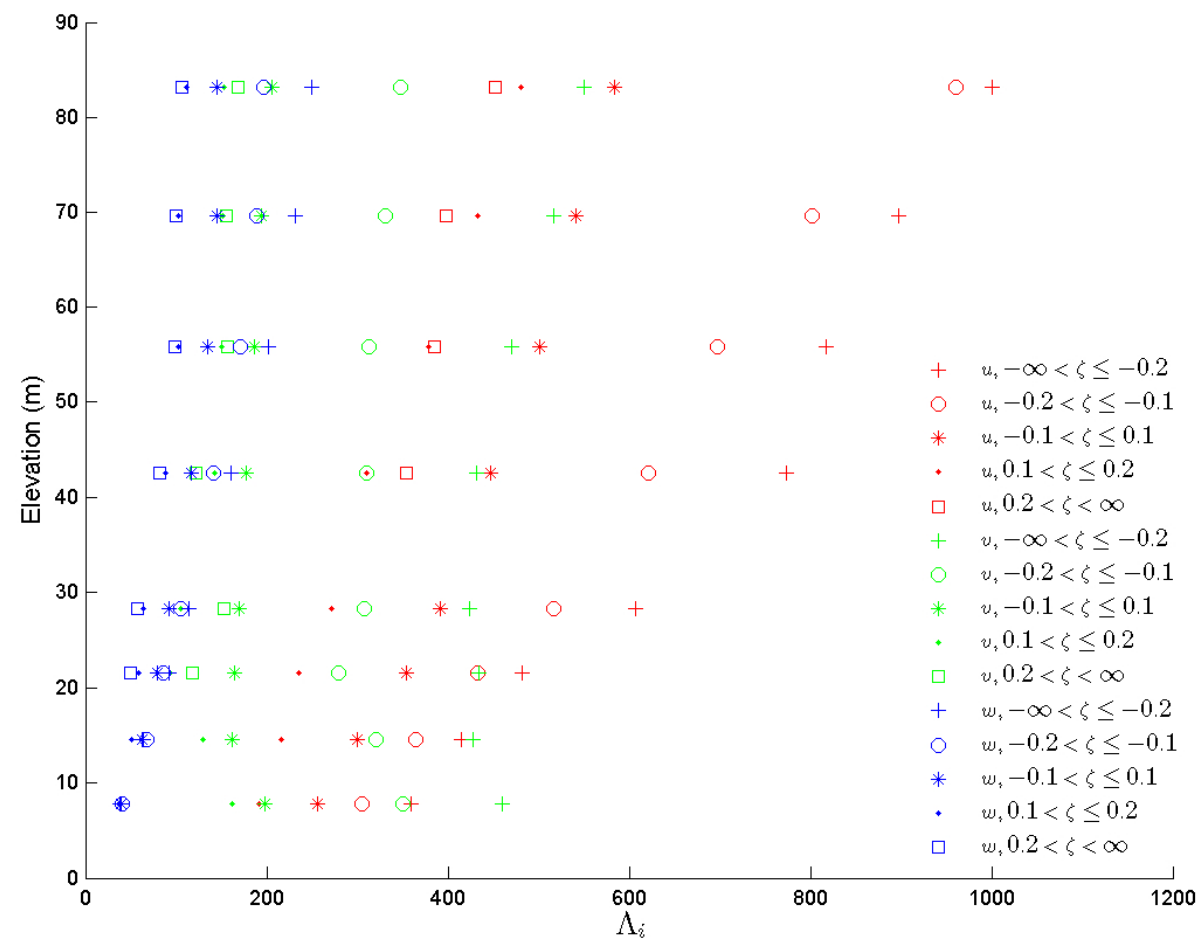

Fig. 6 Same as Fig. 5 except for the mean peak wavelengths, $\Lambda_{\mathrm{i}}, i=u, v, w$ 
Table 4 and Figs. 5 and 6 show the following features for the mean value of the non-dimensional peak frequencies $\overline{\mathrm{N}_{\mathrm{i}}}$ and mean peak wavelengths $\overline{\Lambda_{\mathrm{i}}}$.

1. The values of spectral peaks $\overline{\mathrm{N}}_{\mathrm{i}}, i=u, v, w$ increase with increasing stability at a fixed level. For example, $\overline{\mathrm{N}_{\mathrm{w}}}$ at level $\mathrm{H}$ increases from 0.334 for very unstable conditions to 0.786 for the very stable category. Likewise, the mean values of peak wavelength at a fixed level decrease with stability (Table 4). For instance, the mean peak wavelength of $w$ at level $\mathrm{H}$ decreases from $249.5 \mathrm{~m}$ to $105.9 \mathrm{~m}$.

2. Both $\overline{\mathrm{N}_{\mathrm{i}}}$ and $\overline{\Lambda_{\mathrm{i}}}$ increase with height, as evidenced in Figs. 5 and 6 . For instance, $\overline{\mathrm{N}_{\mathrm{w}}}$ increases from 0.203 at level $\mathrm{A}$ to 0.334 at level $\mathrm{H}$, while $\overline{\Lambda_{\mathrm{w}}}$ goes from $38.5 \mathrm{~m}$ to $249.5 \mathrm{~m}$ (Table 4).

In order to quantify the impact of the atmospheric stability on the spectral peaks, we have calculated the values of $\Delta N_{i}, \Delta \Lambda_{i}$, and $R_{i}$, as defined by Eqs. 9, 10, and 11 from Table 4, where the subscripts max and min indicate the maximum and minimum of the 5 stability categories at each instrument height. These values are listed in Table 5. 
Table 5 Impact on the peak frequencies, $\Delta \mathrm{N}_{\mathrm{i}}$, the peak wavelengths, $\Delta \Lambda_{\mathrm{i}}$ and their relative percentage,

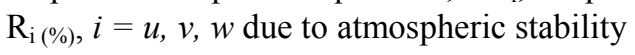

\begin{tabular}{|c|c|c|c|c|}
\hline & & $\mathbf{u}$ & $\mathbf{v}$ & $\mathbf{w}$ \\
\hline \multirow{3}{*}{ A } & $\Delta N_{i}$ & 0.0191 & 0.0312 & 0.0177 \\
\hline & $\Delta \Lambda_{i}$ & 168.2 & 297.0 & 3.33 \\
\hline & $R_{i(\%)}$ & 61.1 & 95.7 & 8.7 \\
\hline \multirow{3}{*}{ B } & $\Delta N_{i}$ & 0.0322 & 0.0785 & 0.0727 \\
\hline & $\Delta \Lambda_{i}$ & 198.2 & 298.5 & 17.1 \\
\hline & $R_{i(\%)}$ & 62.8 & 107.0 & 28.8 \\
\hline \multirow{3}{*}{$\mathrm{C}$} & $\Delta N_{i}$ & 0.0468 & 0.1789 & 0.1952 \\
\hline & $\Delta \Lambda_{i}$ & 246.9 & 340.2 & 41.6 \\
\hline & $R_{i(\%)}$ & 68.8 & 128.8 & 58.8 \\
\hline \multirow{3}{*}{ D } & $\Delta N_{i}$ & 0.0577 & 0.2032 & 0.2477 \\
\hline & $\Delta \Lambda_{i}$ & 336.0 & 318.9 & 57.32 \\
\hline & $R_{i(\%)}$ & 76.5 & 120.7 & 66.8 \\
\hline \multirow{3}{*}{$\mathrm{E}$} & $\Delta N_{i}$ & 0.0819 & 0.2491 & 0.2516 \\
\hline & $\Delta \Lambda_{i}$ & 463.4 & 309.2 & 78.3 \\
\hline & $R_{i(\%)}$ & 85.5 & 111.7 & 64.5 \\
\hline \multirow{3}{*}{$\mathrm{F}$} & $\Delta N_{i}$ & 0.0790 & 0.2521 & 0.2877 \\
\hline & $\Delta \Lambda_{i}$ & 438.2 & 320.3 & 103.4 \\
\hline & $R_{i(\%)}$ & 73.3 & 103.1 & 68.6 \\
\hline \multirow{3}{*}{ G } & $\Delta N_{i}$ & 0.0972 & 0.3232 & 0.3942 \\
\hline & $\Delta \Lambda_{i}$ & 498.5 & 364.2 & 131.2 \\
\hline & $R_{i(\%)}$ & 77.0 & 109.0 & 79.1 \\
\hline \multirow{3}{*}{$\mathrm{H}$} & $\Delta N_{i}$ & 0.1006 & 0.3947 & 0.4525 \\
\hline & $\Delta \Lambda_{i}$ & 547.3 & 397.5 & 143.6 \\
\hline & $R_{i(\%)}$ & 75.4 & 113.2 & 80.8 \\
\hline \multirow{3}{*}{ Average } & $\Delta N_{i}$ & 0.0643 & 0.2139 & 0.2399 \\
\hline & $\Delta \Lambda_{i}$ & 362.1 & 330.7 & 71.98 \\
\hline & $\left.R_{i} \%\right)$ & 72.5 & 111.1 & 57.0 \\
\hline
\end{tabular}

Table 5 indicates that the atmospheric stability can cause an average of $43-71 \%$ variation in spectral peaks, both in the mean peak frequencies and mean peak wavelengths. It has the largest effects on the $v$ spectra. The stability impacts on the mean spectral peaks have more or less the same degree for the different levels, except for the lowest level $w$ spectra, with only $8 \%$ change on average. This shows that atmospheric stability impacts are stronger and more significant than urban canopy inhomogeneity, indicated by comparing Table 5 with Table 3, particularly for upper levels.

To further investigate the relationship between the non-dimensional peak frequency $N_{i}$ and the atmospheric stability, we have used an exponential expression which is 


$$
N_{i}=a|\zeta|^{b}+c
$$

where $a, b$, and $c$ are constants determined by observed data. The data from 3 levels (levels E, F, and $\mathrm{G}$ ) have been lumped together for the curve fitting of Eq. 12, with results presented in Fig. 7. To fit Eq. 12, 30 bin averages of $N_{i}$ and $z / L$ have been used, 15 to fit the positive data and 15 to fit the negative $z / L$ data. Figure 7 shows a representative relationship between $N_{i}$ and $z / L$ in a layer (42.5-69.7 $\mathrm{m}$ ) above the Oklahoma urban canopy, with a displacement height of $19.9 \mathrm{~m}$ in the wind direction range of $120-210^{\circ}$. These results are similar to those over flat land (Figure 2.9, Kaimal and Finnigan 1994).
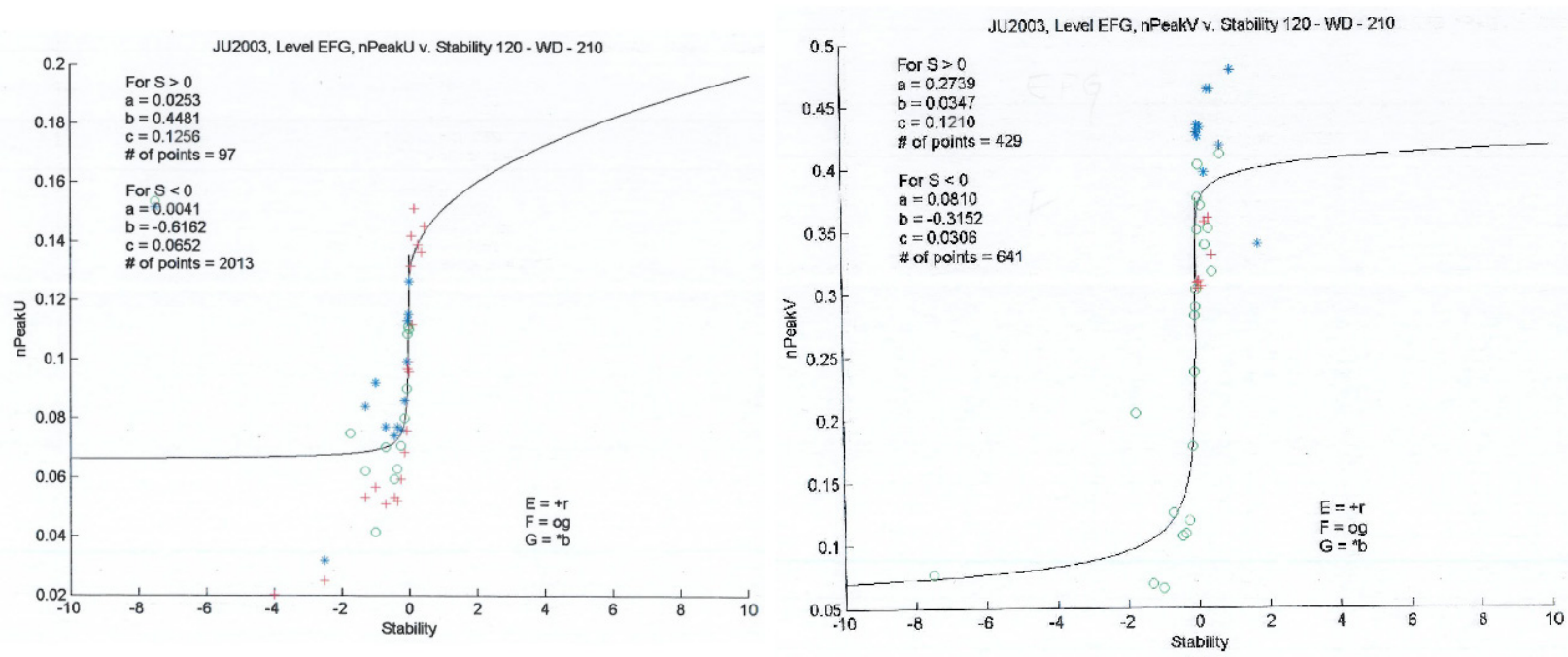

a
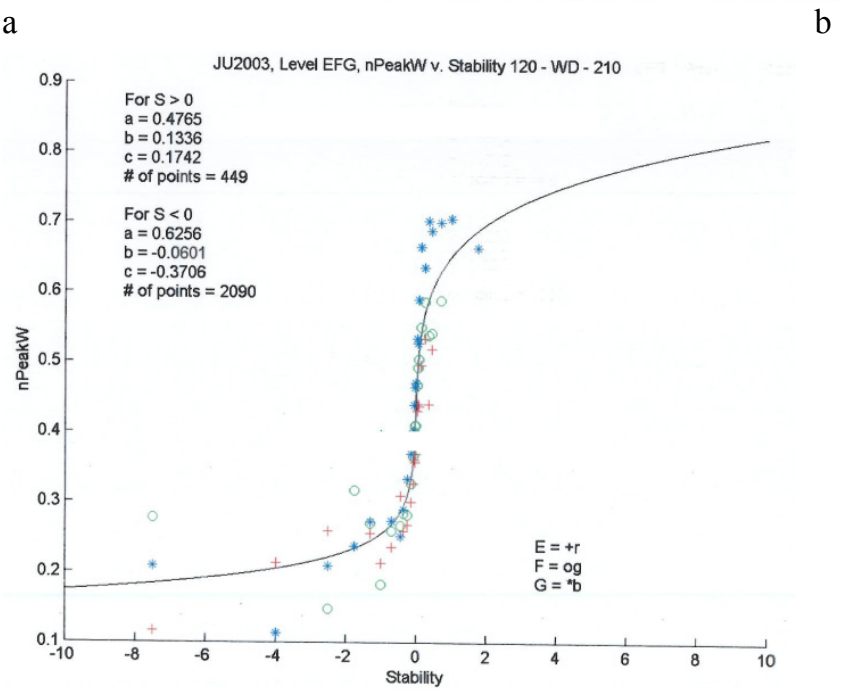

$\mathrm{c}$

Fig. 7 Variation of the spectral peaks with the stability $(z / L)$ for $\bar{N}_{\mathrm{u}}$ (Fig. 7a), $\bar{N}_{\mathrm{v}}$ (Fig. 7b), and $\bar{N}_{\mathrm{w}}$ (Fig. 7c) composed from 3 levels (level E,F,G) for $120^{\circ}<\mathrm{WD}<210^{\circ}$. The curves in the Fig. 7 are from the empirical curve fitting, Eq. 12. 


\subsection{Observational Height (z) Effects on the Spectral Peaks}

Figures 3, 4, 5, and 6 have clearly shown the effects of observational height $(z)$ on the spectral peaks. We mentioned earlier that both the mean non-dimensional peak frequencies and the peak wavelengths increase with $z$ for all 3 WD sectors (Table 2) and for all 5 atmospheric stability classes (Table 4). Here we can compare the relative importance of the 3 factors by using the index $R_{i}$, defined in (10).

The 8 level averaged $R_{i}$ values for the 3 factors (WD, stability, and $z$ ) are listed in Table 6 .

$$
\begin{aligned}
& \text { Table } 6 \text { Comparison of relative effects of the } \\
& \text { wind direction (WD), atmospheric } \\
& \text { stability (z/L), and observational height } \\
& \text { (z) on the u-, v-, and w-spectral peaks }
\end{aligned}
$$

\begin{tabular}{|c|c|c|l|}
\hline & U spectra & V spectra & W spectra \\
\hline WD & $24.5 \%$ & $33.9 \%$ & $17.7 \%$ \\
\hline$z / L$ & $72.5 \%$ & $111.1 \%$ & $57.0 \%$ \\
\hline$z$ & $120.7 \%$ & $166.0 \%$ & $93.9 \%$ \\
\hline
\end{tabular}

The averaged values of $R_{i}$ in the first 2 lines of Table 6 are from the last lines of Tables 2 and 4 , respectively. The averaged values of $R_{i}$ in the third line of Table 6 are based on Table 4 for the stable, near-neutral, and unstable stratification. From the numbers listed above, it is clear that the observation height plays a dominant role for spectral peaks. For example, the change of $\mathrm{z}$ from $7.8 \mathrm{~m}$ to $83.2 \mathrm{~m}$ can affect the average peak value of $\mathrm{w}$-spectra by $93.9 \%$, while the change in the stability $(\mathrm{z} / \mathrm{L})$ from very stable to very unstable stratification, or the change in the wind direction can cause the average peak values by $57.0 \%$ and $17.7 \%$, respectively.

The spectral fit parameters, $a_{i}$ and $b_{i}$, also change with $z$ significantly. Figure 8 exhibits the average spectral fits of the $u, v$, and $w$ spectra at 8 levels (A through $\mathrm{H}$ ) for the near-neutral conditions. Notice that the average $u, v$, and $w$ spectra at different levels are plotted with different colors. The figures cover $120^{\circ}<\mathrm{WD}<210^{\circ}$. Related to Fig. 8 is Table 7, which provides the mean near-neutral spectra parameters, $\overline{\mathrm{a}_{\mathrm{i}}}$ and $\overline{\mathrm{b}_{\mathrm{i}}}$ in $(1), i=u, v, w$, their standard deviations $\left(\sigma_{a}, \sigma_{b}\right)$, number of runs (\#), corresponding mean peak frequencies $\overline{\mathrm{N}}_{\mathrm{i}}$ and mean peak wavelengths $\overline{\Lambda_{\mathrm{i}}}$. 


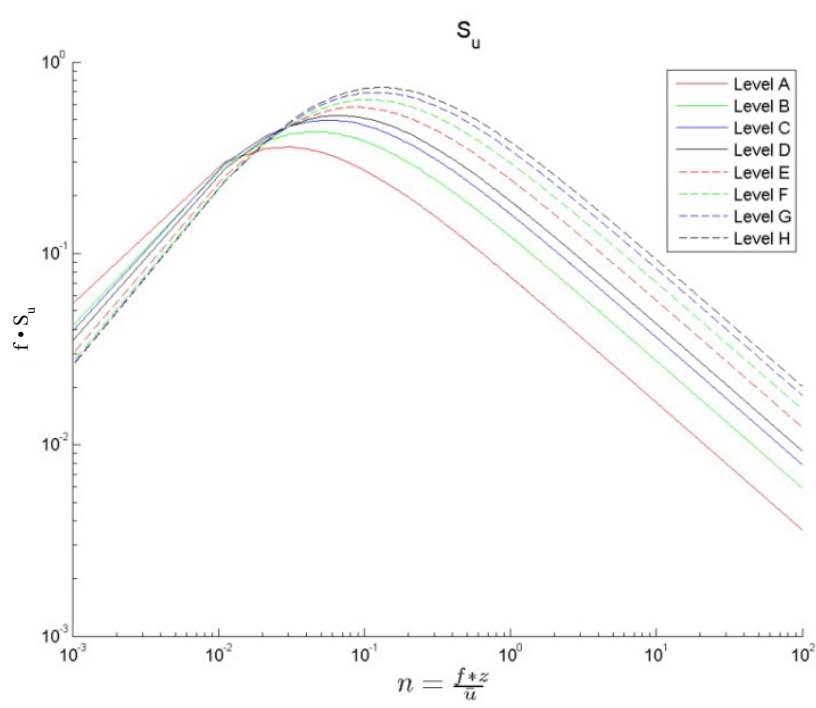

$S_{v}$

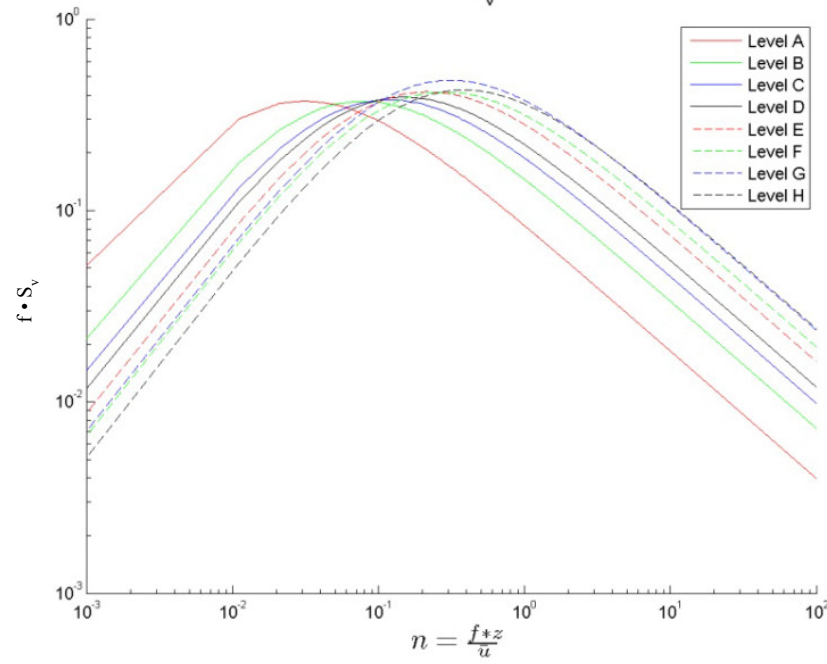

$\mathrm{S}_{\mathrm{w}}$

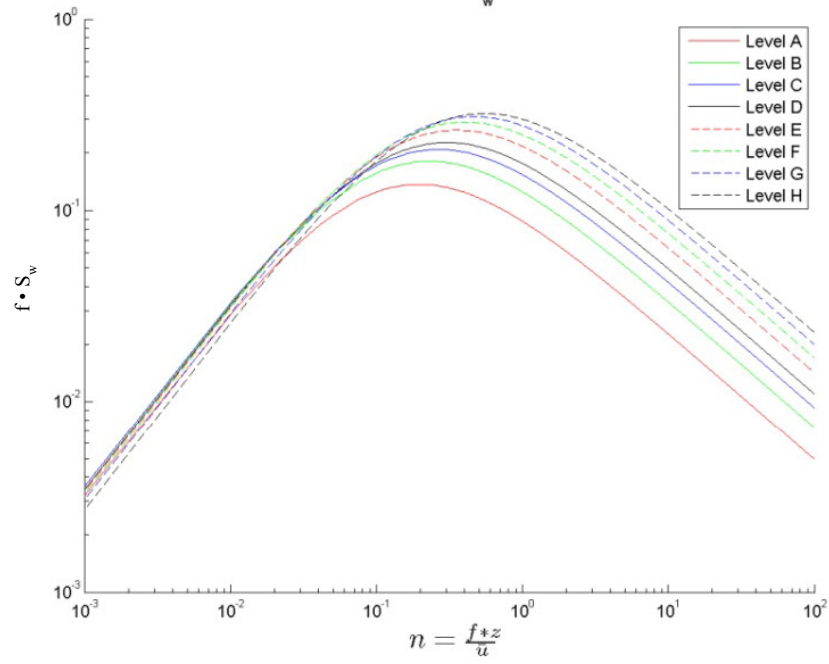

Fig. 8 The average spectra of $u, v$, and $w$ at eight levels for the near-neutral conditions 
Figure 8 clearly shows the systematic variation of these spectral parameters with height above the ground. All of the peaks of $u, v$, and $w$ spectra move toward high frequency from lower levels to higher levels. Table 7 shows that those mean peak frequencies and mean peak wavelengths increase with height. For example, the non-dimensional peak frequency of near-neutral $w$ spectra increases from 0.194 at $7.8 \mathrm{~m}$ to 0.544 at $83.2 \mathrm{~m}$. The corresponding average peak wavelengths increase from $40.2 \mathrm{~m}$ at $7.8 \mathrm{~m}$ to $152.9 \mathrm{~m}$ at $83.2 \mathrm{~m}$.

Table 7 Mean near-neutral spectral parameters, $\overline{\mathrm{a}_{\mathrm{i}}}$ and $\overline{\mathrm{b}_{\mathrm{i}}}$ in $(1), i=u, v, w$, their standard deviations $\left(\sigma_{\mathrm{a}}\right.$ and $\left.\sigma_{\mathrm{b}}\right)$, number of runs $(\#)$, corresponding mean peak frequencies $\overline{\mathrm{N}_{\mathrm{i}}}$, and mean peak wavelengths $\overline{\Lambda_{i}}$

\begin{tabular}{|c|c|c|c|c|c|c|c|}
\hline \multicolumn{8}{|c|}{$\mathrm{u}$} \\
\hline Level & $\overline{\mathrm{a}_{\mathrm{i}}}$ & $\overline{\mathrm{b}_{\mathrm{i}}}$ & $\sigma_{a}$ & $\sigma_{\mathrm{b}}$ & $\#$ & $\overline{\mathrm{N}_{\mathrm{i}}}$ & $\overline{\Lambda_{\mathrm{i}}}$ \\
\hline $\mathrm{A}$ & 59.503 & 53.8397 & 40.8961 & 18.8265 & 805 & 0.0279 & 280.0 \\
\hline B & 44.2428 & 33.3098 & 31.9081 & 12.2455 & 761 & 0.045 & 324.2 \\
\hline $\mathrm{C}$ & 41.1913 & 26.9471 & 33.1569 & 11.0933 & 669 & 0.0557 & 386.2 \\
\hline $\mathrm{D}$ & 36.5341 & 22.7017 & 29.6500 & 10.6749 & 652 & 0.0661 & 428.3 \\
\hline E & 30.7313 & 17.263 & 27.8519 & 7.9642 & 595 & 0.0869 & 489.1 \\
\hline $\mathrm{F}$ & 27.9296 & 14.3053 & 23.4567 & 5.7995 & 552 & 0.1049 & 532.1 \\
\hline G & 26.8645 & 12.6385 & 23.8325 & 5.3274 & 531 & 0.1187 & 587.2 \\
\hline $\mathrm{H}$ & 26.4446 & 11.7285 & 27.6094 & 5.5186 & 476 & 0.1279 & 650.6 \\
\hline \multicolumn{8}{|c|}{$\mathrm{v}$} \\
\hline Level & $\overline{\mathrm{a}_{\mathrm{i}}}$ & $\overline{b_{i}}$ & $\sigma_{\mathrm{a}}$ & $\sigma_{\mathrm{b}}$ & \# & $\overline{\overline{N_{i}}}$ & $\overline{\Lambda_{i}}$ \\
\hline $\mathrm{A}$ & 56.0646 & 48.8256 & 115.1372 & 49.491 & 805 & 0.0307 & 253.9 \\
\hline $\mathrm{B}$ & 22.240 & 19.5067 & 31.0581 & 14.3552 & 761 & 0.0769 & 189.9 \\
\hline $\mathrm{C}$ & 14.857 & 12.7861 & 16.0955 & 6.6412 & 669 & 0.1173 & 183.3 \\
\hline $\mathrm{D}$ & 11.928 & 9.9605 & 13.2049 & 5.4454 & 652 & 0.1506 & 187.9 \\
\hline E & 8.8595 & 6.9298 & 23.2993 & 7.7251 & 595 & 0.2165 & 196.3 \\
\hline $\mathrm{F}$ & 6.7696 & 5.3005 & 4.2196 & 1.7542 & 552 & 0.2830 & 197.2 \\
\hline G & 7.1111 & 4.842 & 25.3765 & 7.2713 & 531 & 0.3098 & 225.0 \\
\hline $\mathrm{H}$ & 5.1598 & 3.9461 & 2.8262 & 1.1992 & 476 & 0.3801 & 218.9 \\
\hline \multicolumn{8}{|c|}{$\mathrm{w}$} \\
\hline Level & $\overline{\mathrm{a}_{\mathrm{i}}}$ & $\overline{b_{i}}$ & $\sigma_{a}$ & $\sigma_{b}$ & $\#$ & $\overline{\mathrm{N}_{\mathrm{i}}}$ & $\overline{\Lambda_{\mathrm{i}}}$ \\
\hline A & 3.2521 & 7.7382 & 1.6606 & 1.3018 & 805 & 0.1938 & 40.24 \\
\hline B & 3.6413 & 6.5633 & 1.8548 & 1.1597 & 761 & 0.2285 & 63.88 \\
\hline $\mathrm{C}$ & 3.6213 & 5.6603 & 1.8499 & 1.0342 & 669 & 0.2650 & 81.13 \\
\hline $\mathrm{D}$ & 3.4702 & 4.9885 & 1.8359 & 0.9646 & 652 & 0.3007 & 94.12 \\
\hline $\mathrm{E}$ & 3.4229 & 4.2448 & 1.8160 & 0.8555 & 595 & 0.3534 & 120.3 \\
\hline $\mathrm{F}$ & 3.3235 & 3.7405 & 1.6930 & 0.8028 & 552 & 0.4010 & 139.2 \\
\hline $\mathrm{G}$ & 3.0773 & 3.2389 & 1.4198 & 0.6842 & 531 & 0.4631 & 150.5 \\
\hline $\mathrm{H}$ & 2.7193 & 2.7570 & 1.1437 & 0.6147 & 476 & 0.5441 & 152.9 \\
\hline
\end{tabular}




\section{Conclusion}

Previous methods for determining the spectral peaks have their limitations. The direct outputs from FFT are very noisy, which cannot provide accurate estimates for spectral peaks. The bin average method has limited resolution and, therefore, limited accuracy for evaluation of spectral peaks. Our simple analytical form to model one-dimensional velocity spectra appears very useful and dependable. Different analytical expressions (Sorbjan, 1989), of course, can be used to model velocity spectra, but they are not necessarily better than the simple one, such as Eq. 1 . Based on this simple analytical expression, the one-dimensional velocity spectral characteristics from the Oklahoma City (JU2003) sonic measurements have been analyzed extensively.

In the tower layer (7.8-83.2 $\mathrm{m}$ ) at Oklahoma City downtown, the mean values of dimensionless spectral peaks can vary widely $-0.022-0.184$ for $u$ spectra, $0.017-0.546$ for $v$, and $0.203-0.786$ for $w$. The corresponding mean peak wavelengths can be 191-1000 $\mathrm{m}$ for $u$ spectra, $94-550 \mathrm{~m}$ for $v$, and $37-250 \mathrm{~m}$ for $w$, depending on wind direction, atmospheric stability $(z / L)$, and the observation height $(z)$. There are 3 factors, at least, that have significant impacts on these mean spectral peaks. 1) The wind direction factor which takes the complex influences of the building distribution along the fetch. 2) The atmospheric stability $(z / L)$ factor which causes $\overline{\mathrm{N}_{\mathrm{i}}}$ increases with the stability (larger $z / L$ value) and $\overline{\Lambda_{\mathrm{i}}}$ decreases with stability, $i=u, v$, and $w$, as evidenced in Table 4. This factor seems more pronounced than the first factor. 3) The observation height $(z)$ factor, which is a more pronounced influence than either the stability or wind direction.

It is very interesting that the spectral peak locations under near neutral conditions vary with height systematically, as shown in Fig. 8. It should be pointed out that the classic MoninObukhov parameter $(z / L)$ appears to be not the only factor in determining those spectral peaks for the inhomogeneous urban canopy flow, such as in the Oklahoma City case. It is still a large challenge to formulate a theoretical similarity formulation, if any, for this complex canopy flow. 


\section{References}

Allwine KJ, Leach MJ, Stockham LW, Shinn JS, Hosker RP, Bowers JF, Pace JC. Overview of joint urban 2003 - an atmospheric dispersion study in Oklahoma City. AMS Symposium on Planning, Nowcasting, and Forecasting in the Urban Zone, 11-15 January 2004, Seattle, WA, 2004.

Busch NE, Panofsky HA. Recent spectra of atmospheric turbulence. Q J R Meteorol. Soc. 1968;94:132-148.

Chang SS, Huynh GD, Klipp CL, Williamson CC, Garvey DM, Wang Y. Observational study of turbulence spectra for joint urban 2003. Amer. Meteor. Soc. $5^{\text {th }}$ Symposium on Urban Environment, 23-27 Aug., Vancouver, BC, Canada, 3.5, 2004.

Chang Sam, Huynh Giap. A comparison of roughness parameters for Oklahoma City from different evaluation methods. Seventh Symposium on the Urban Environment, 10-13 September, 2007, San Diego, CA, American Meteorological Society.

Chang S, Huynh G, Tofsted D. Turbulence characteristics in Oklahoma City measured from a $83 \mathrm{~m}$ pseudo tower. The $89^{\text {th }}$ AMS Annual Meeting, 11-15 January 2009, Phoenix, Arizona, USA.

Chang Sam, Huynh G, Tofsted D, Garvey D, Williamson C, Li D. Urban turbulence spectra from field observation. The $16^{\text {th }}$ Conference on Air Pollution Meteorology, 2010 AMS Annual Meeting, 17-21 January 2010, Atlanta, Georgia USA.

Feigenwinter C, Vogt R, Parlow E. Vertical structure of turbulence above an urban canyon, pp $472-473$ in Preprints of the $12^{\text {th }}$ symposium of boundary layer and turbulence. Vancouver, Canada, July 28-August 1, 1997, American Meteorological Society, Boston, USA.

Feigenwinter C, Vogt R, Parlow E. Vertical structure of selected turbulence characteristics above an urban canopy. Theoretical and Applied Climatology. 1999;62:51-63.

Gouveia FJ, Leach MJ, Shinn JM, Ralph WE. Use of a large crane for wind and tracer profiles in an urban setting. Journal of Atmospheric and Oceanic Technology. 2007;24:1750-1756.

Kaimal JC, Finnigan JJ. Atmospheric Boundary Layer Flows, Their Structure and Measurement. Oxford University Press, 1994, 289 pp.

Lee X, Massman W, Law B. Handbook of micrometeorology, 2004, pp 250.

Lundquist JK, Shinn JH, Gouveia F. Observations of turbulent kinetic energy dissipation rate in the urban environment. 84th AMS Annual Meeting, 11-15 January 2004, Seattle, WA, 2004. 
Panofsky Hans A. Dutton John A. Atmospheric turbulence. John Wiley \& Sons, 1984, 397 pp.

Roth M. Review of atmospheric turbulence over Cities. Q J R. Meteorol. Soc. 2000;126:941990.

Sorbja, Z. Structure of the atmospheric boundary layer. Prentice-Hall, Inc., 1989, 317 pp.

Wilson D Keith. A new model for turbulence spectra and correlations based on meijer's Gfunctions. Adelphi (MD): US Army Research Laboratory (US). February 1998. Report No.: ARL-TN-104. 


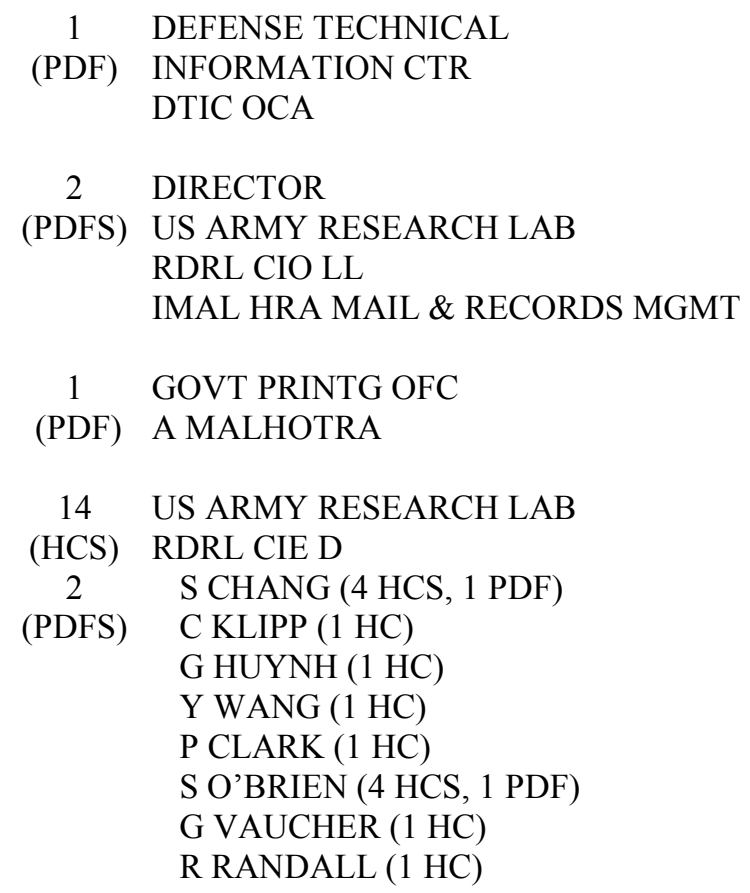


INTENTIONALLY LEFT BLANK. 